\title{
Spacing of Hydraulically Fractured Horizontal Laterals in Low Permeability Formations
}

\author{
Franck Donfack
}

Follow this and additional works at: https://researchrepository.wvu.edu/etd

\section{Recommended Citation}

Donfack, Franck, "Spacing of Hydraulically Fractured Horizontal Laterals in Low Permeability Formations" (2014). Graduate Theses, Dissertations, and Problem Reports. 5503.

https://researchrepository.wvu.edu/etd/5503

This Thesis is protected by copyright and/or related rights. It has been brought to you by the The Research Repository @ WVU with permission from the rights-holder(s). You are free to use this Thesis in any way that is permitted by the copyright and related rights legislation that applies to your use. For other uses you must obtain permission from the rights-holder(s) directly, unless additional rights are indicated by a Creative Commons license in the record and/ or on the work itself. This Thesis has been accepted for inclusion in WVU Graduate Theses, Dissertations, and Problem Reports collection by an authorized administrator of The Research Repository @ WVU. For more information, please contact researchrepository@mail.wvu.edu. 


\title{
Spacing of Hydraulically Fractured Horizontal Laterals in Low Permeability Formations
}

\author{
Franck Donfack \\ Thesis submitted \\ to the Benjamin M. Statler College of Engineering and Mineral Resources \\ at West Virginia University \\ in partial fulfillment of the requirements for the degree of \\ Master of Science in \\ Petroleum and Natural Gas Engineering
}

\author{
Khashayar Aminian, Ph.D., Chair \\ Samuel Ameri, M.S.. \\ Daniel Della-Giustina, Ph.D.
}

Department of Petroleum and Natural Gas Engineering

Morgantown, West Virginia

2014

Copyright 2014 Franck Donfack 


\section{ABSTRACT \\ Spacing of Hydraulically Fractured Horizontal Laterals in Low Permeability Formations}

\section{Franck Donfack}

The discovery of unconventional reservoirs such as tight gas sands and shale gas, the resolve for the United States to become independent of foreign hydrocarbons, toppled with depleting conventional fields around the world, has pushed for new technologies and effective and efficient approaches in unconventional reservoirs long-term production to supply their ever-growing demand.

Horizontal drilling along with hydraulic fracturing are the two most popular methods used to render low-permeability formations such as the Marcellus Shale economically productive. Nowadays, coupled with horizontal drilling and hydraulic fracturing, new strategies and tools such as coil tubing and multilateral horizontal wells are being strategized and used for unconventional reservoirs as well as conventional reservoirs to maximize recovery. However, the understanding of the production performance of recently drilled hydraulically fractured horizontal wells in low-permeability formations represents a challenge because of the lack extensive production history on these new producing wells. The same is true about the multi-lateral horizontal wells, though they have great potential for improving the recovery. The objective of this study was to conduct a modeling study, to investigate the impact of wells spacing on the production performance of hydraulically fractured multi-lateral horizontal wells in low permeability formations. 


\section{ACKNOWLEDGEMENTS}

This thesis research would not have been possible without the help and support of many people.

I am grateful and thankful to my advisor, Dr. Kashy Aminian, for his commitment and his help throughout my research.

I want to dedicate this work to my parents, Mr. and Mme. Donfack, for their relentless support throughout my education.

I would like to thank my committee members, Professor Samuel Ameri Chair of Petroleum \& Natural Gas Engineering Department, and Dr. Daniel Della-Giustina for their presence and guidance. I would also like to thank the Petroleum and Natural Gas Engineering Department of West Virginia University and the rest of its staff and faculties, without forgetting the great faculties and staff of the Benjamin M. Statler College of Engineering and Mineral Resource. 


\title{
TABLE OF CONTENTS
}

\author{
ABSTRACT \\ ACKNOWLEGMENTS \\ DEDICATION \\ TABLE OF CONTENTS \\ LIST OF FIGURES \\ LIST OF TABLES \\ 1. INTRODUCTION \\ 2. LITERATURE REVIEW \\ 2.1 Shale Gas \\ 2.2 Dual Porosity Reservoir \\ 2.3 Horizontal Drilling \\ 2.4 Hydraulic Fracturing \\ 2.4.1 Fracture Orientation \\ 2.4.2 Fracture: Length and Height \\ 2.4.3 Dimensionless Fracture Conductivity \\ 2.5 Multi-Lateral Horizontal Wells \\ 2.5.1 Drainage area \\ 2.5.2 Well-Spacing and Well-Interference
}

3. OBJECTIVE AND METHODOLOGY

3.1 Objectives

3.2 Methodology

3.2.1 Objective 1

3.2.2 Objective 2

4. RESULTS AND DISCUSSIONS

4.1 Objective 1

4.2 Objective 2

5. CONCLUSION

6. REFERENCES

7. APPENDIX

Appendix A (Objective 1 - figures of production results) Appendix B (Objective 2 - figures of production results) Appendix C (Discussions) 


\section{LIST OF TABLES}

Table 1: Comparison of data of shale formation in the U.S

Table 2: Models Parameters used to develop base model

Table 3: Summary of simulation run cases to obtain a model that helps developing our base model

Table 4: Summary of simulation run cases to develop our base model and its two production profiles 


\section{LIST OF FIGURES}

Figure 1: U.S energy production by fuel, 1980-2040

Figure 2: Shale formations in the USA

Figure 3: Marcellus Shale Gas play

Figure 4: Classic theory for double-porosity model

Figure 5: Tradition wells vs. Horizontal drilling

Figure 6: Pad drilling and rig mobility lead to more efficient drilling

Figure 7: Marcellus Shale Hydraulic Fracturing

Figure 8: Fracture propagation perpendicular to the minimum horizontal stress

Figure 9: (1) PKN fracture Geometry; (2) KGD fracture Geometry; (3) Lumped-parameter 3-D modeling showing two semi-ellipses

Figure 10: Figures of well Strategies for Multi-lateral wells

Figure 11: (1) Drainage areas of $1000 \mathrm{ft}$. and $2000 \mathrm{ft}$; (2) Drainage Areas of Horizontal and Vertical wells in a Fractured Reservoir.

Figure 12: Generated base model $8000 \mathrm{ft} . \times 4000 \mathrm{ft}$. (by Eclipse) containing two hydraulically fractured horizontal laterals each with 25 stages.

Figure 13: Generated model $4000 \mathrm{ft} . \times 2000 \mathrm{ft}$. containing one hydraulically fractured horizontal lateral with 13 stages.

Figure A.1: Cumulative Production results vs. Time of 1 hydraulically fractured horizontal lateral(s) - Results of Runs 1, 2, and 3 in Table 4

Figure A.2: Cumulative Production results vs. Time of hydraulically fractured horizontal lateral(s) Results of Runs 4, 5, and 6 in Table 4

Figure A.3: Cumulative Production results vs. Time of hydraulically fractured horizontal lateral(s) Results of Runs 7, 8, and 9 in Table 4

Figure A.4: Cumulative Production results vs. Time of hydraulically fractured horizontal lateral(s) Results of Runs 10, 11, and 12 in Table 4

Figure A.5: Cumulative Production results vs. Time of hydraulically fractured horizontal lateral(s) Results of Runs 13, 14, and 15 in Table 4 
Figure A.6: Cumulative Production results vs. Time of hydraulically fractured horizontal lateral(s) Results of Runs 16, 17, and 18 in Table 4

Figure A.7: Cumulative Production results vs. Time of hydraulically fractured horizontal lateral(s) Results of Runs 19, 20, and 21 in Table 4

Figure A.8: Cumulative Production results vs. Time of hydraulically fractured horizontal lateral(s) Results of Runs 22, 23, and 24 in Table 4

Figure A.9: Cumulative Production results vs. Time of hydraulically fractured horizontal lateral(s) Results of Runs 25 and 26 in Table 4

Figure A.10: Cumulative Production results vs. Time of hydraulically fractured horizontal lateral(s) Results of Runs 27 and 28 in Table 4

Figure B.1: Cumulative Production results vs. Time of hydraulically fractured horizontal lateral(s) Results of Runs 29, 30, and 31 in Table 5

Figure B.2: Cumulative Production results vs. Time of hydraulically fractured horizontal lateral(s) Results of Runs 32, 33, 34, 35, 36, 37, and 38 in Table 5

Figure B.3: Cumulative Production results vs. Time of hydraulically fractured horizontal lateral(s) Results of Runs 39, 40, and 41 in Table 5

Figure B.4: Cumulative Production results vs. Time of hydraulically fractured horizontal lateral(s) Results of Runs 42, 43, and 44 in Table 5

Figure B.5: Cumulative Production results vs. Time of hydraulically fractured horizontal lateral(s) Results of Runs 45, 46, and 47 in Table 5

Figure B.6: Cumulative Production results vs. Time of hydraulically fractured horizontal lateral(s) Results of Runs 48, 49, 51, and 50 in Table 5

Figure B.7: Cumulative Production results vs. Time of hydraulically fractured horizontal lateral(s) Results of Runs 52, 53, and 54 in Table 5 


\section{NOMENCLATURE}

$\mathrm{K}=\mathrm{X}$-direction permeability of the matrix blocks

$\mathrm{S}_{\mathrm{o}}, \mathrm{S}_{\mathrm{w}}, \mathrm{S}_{\mathrm{g}}=$ oil, water, and gas saturations

$\mathrm{B}=$ formation volume factor, $\mathrm{RB} / \mathrm{STB}$

$\mu=$ viscosity, $\mathrm{cp}$

$\mathrm{h}=$ thickness, $\mathrm{ft}$

$\mathrm{k}=$ permeability, $\mathrm{md}$

$\phi=$ porosity, fraction of bulk volume

$\mathrm{p}_{\mathrm{i}}=$ initial pressure, $\mathrm{psi}$

$\mathrm{p}_{\mathrm{wf}}=$ wellbore flowing pressure, $\mathrm{psi}$

$\mathrm{T}=$ temperature, $\left({ }^{0} \mathrm{R}\right)$

$\mathrm{t}=$ time, years

$\mathrm{C}_{\mathrm{fd}}=$ dimensionless fracture conductivity,

$\mathrm{K}_{\mathrm{f}} \mathrm{W}=$ fracture conductivity

$\mathrm{k}_{\mathrm{f}}$-proppant permeability

$\mathrm{w}_{\mathrm{f}}=$ fracture width, in

$\mathrm{x}_{\mathrm{f}}=$ fracture half length, $\mathrm{ft}$

h.l. or H.L or H.F = fracture half- length

w.f or W.F = width of fracture

$\mathrm{L}=$ length of drainage area, $\mathrm{ft}$

$\mathrm{w}=$ width of drainage area, $\mathrm{ft}$

frac. $=$ fracture

Cum. Prod. = cumulative production, Mscf

in. $=$ inches

$\mathrm{ft} .=$ feet 


\section{INTRODUCTION}

The discovery of unconventional reservoirs such as tight gas sands and shale gas has been the results of the new technologies, which have provided effective and efficient approaches for the economic development of these resources. Horizontal drilling along with multiple hydraulic fracturing are the two major advanced technologies which are commonly employed for economic development of the ultra-low permeability formations such as shale.

Coupled with horizontal drilling and hydraulic fracturing, coil tubing and multi-lateral horizontal wells are new strategies and techniques used for achieving larger drainage areas in the unconventional reservoirs, as well as conventional reservoirs. But drilling and production enhancement operations are only a fraction of developing a reservoir. Production and reservoir analysis, which are ongoing studies that dictate the operations or work-overs to be done throughout the life cycle of a reservoir, are complex and unique for each reservoir; even more so for reservoirs with hydraulically fractured horizontal laterals, because of the lack of production data history collected on these recently producing wells (Nelson, B. et al, 2014).

The goal of this research thesis was to investigate the impact of well spacing on the production performance of hydraulically fractured horizontal laterals in low permeability formations such as Marcellus shale, aided by conducting relevant modeling studies and their respective simulated production profiles. 


\section{LITERATURE REVIEW}

The United States desire to become independent of the foreign hydrocarbons coupled with depleting conventional fields around the world and with the growing demand for natural gas resources, have been the driver for development of the unconventional reservoirs. Coal bed methane, tight gas, and shale gas are the current unconventional reservoirs proven to be economically productive. The exploration and development of these unconventional resources will permit the U.S to meet its demand, and so, will gradually reduce its import needs as demonstrated in Figure 1.

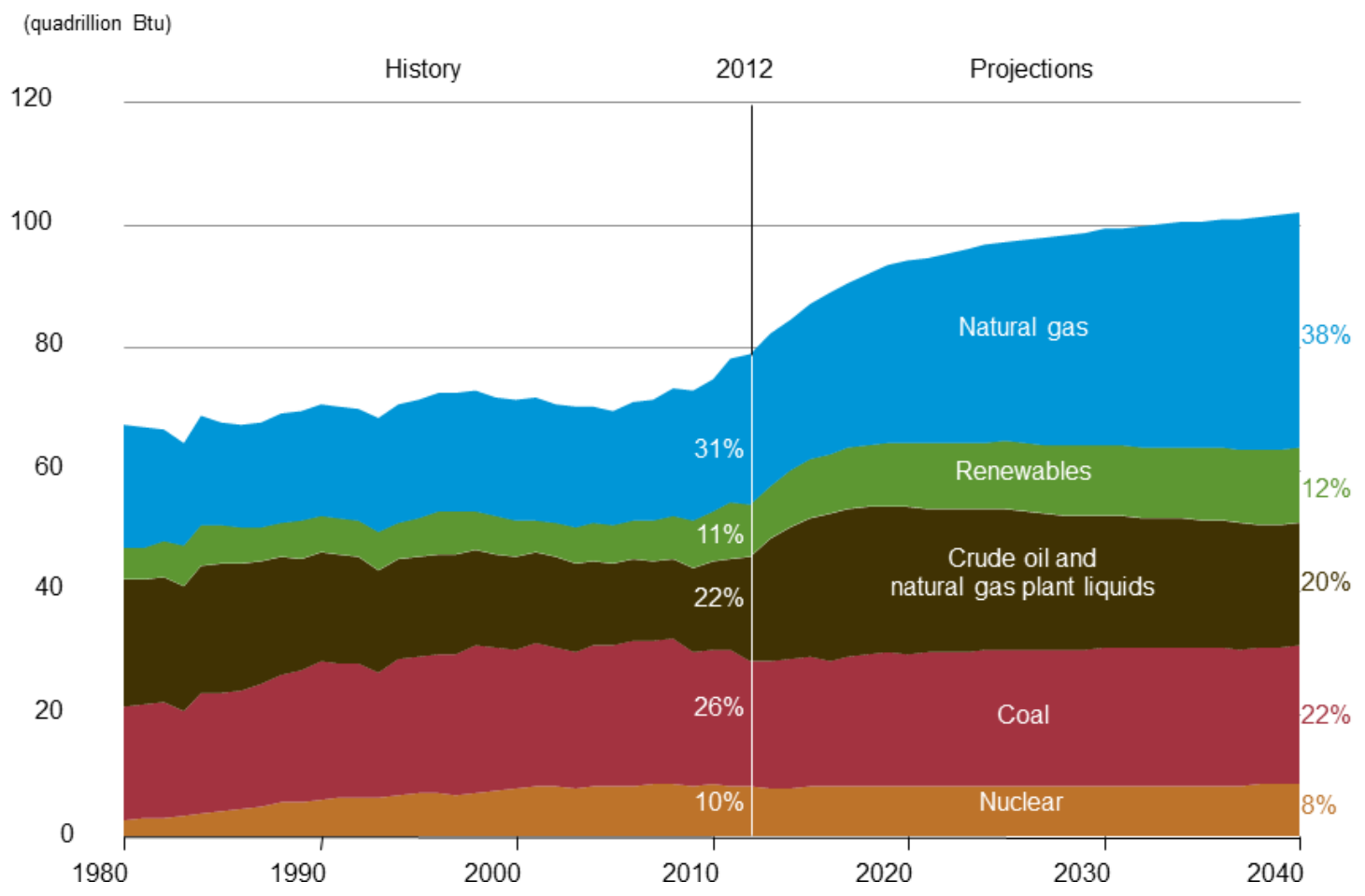

Figure 1: U.S energy consumption by fuel, 1980-2040 (EIA, 2013) 


\subsection{Shale Gas:}

The abundance of unconventional reservoirs will not only enable the U.S to meet its domestic natural gas demand for years to come but will result in natural gas surplus. This increase in production is already expected to continue till 2040 (EIA, 2013). Unconventional reservoirs are widely spread across the country as Figure 2 illustrates: the southern part of U.S with the Barnett Shale (Texas); the Northwestern part of the country (Colorado) with the Piceance Oil shale Basin; the Midwestern part of the U.S with the New Albany shale (Illinois Basin), and the Antrim shale (Michigan Basin); and in the Northeast with the Marcellus Shale (Appalachian Basin).

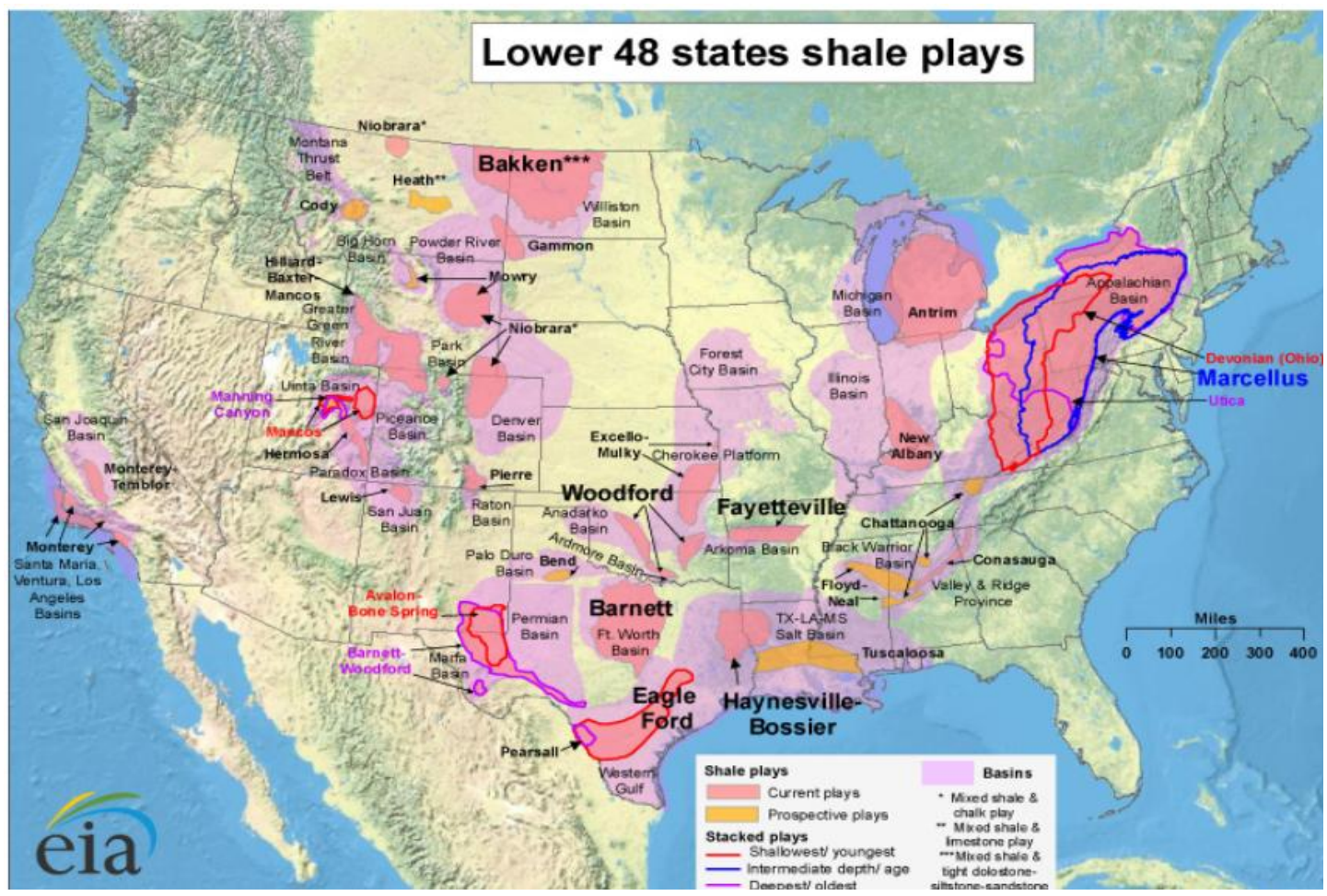

Figure 2: Shale formations in the USA (EIA, 2011)

As seen in Figure 3, the Marcellus Shale covers an area of around 50,000,000 Acres in Pennsylvania, New York, Ohio, Maryland, and West Virginia. It is estimated to have an average thickness of 50 feet

(Belvalkar, R. \& Oyewole, S., 2010), with 400 trillion cubic feet of technically recoverable reserves of 
natural gas (EIA, 2011). Despite its abundance, the Marcellus Shale presents a challenge to overcome during its production because of its low permeability and low (and dual) porosity.

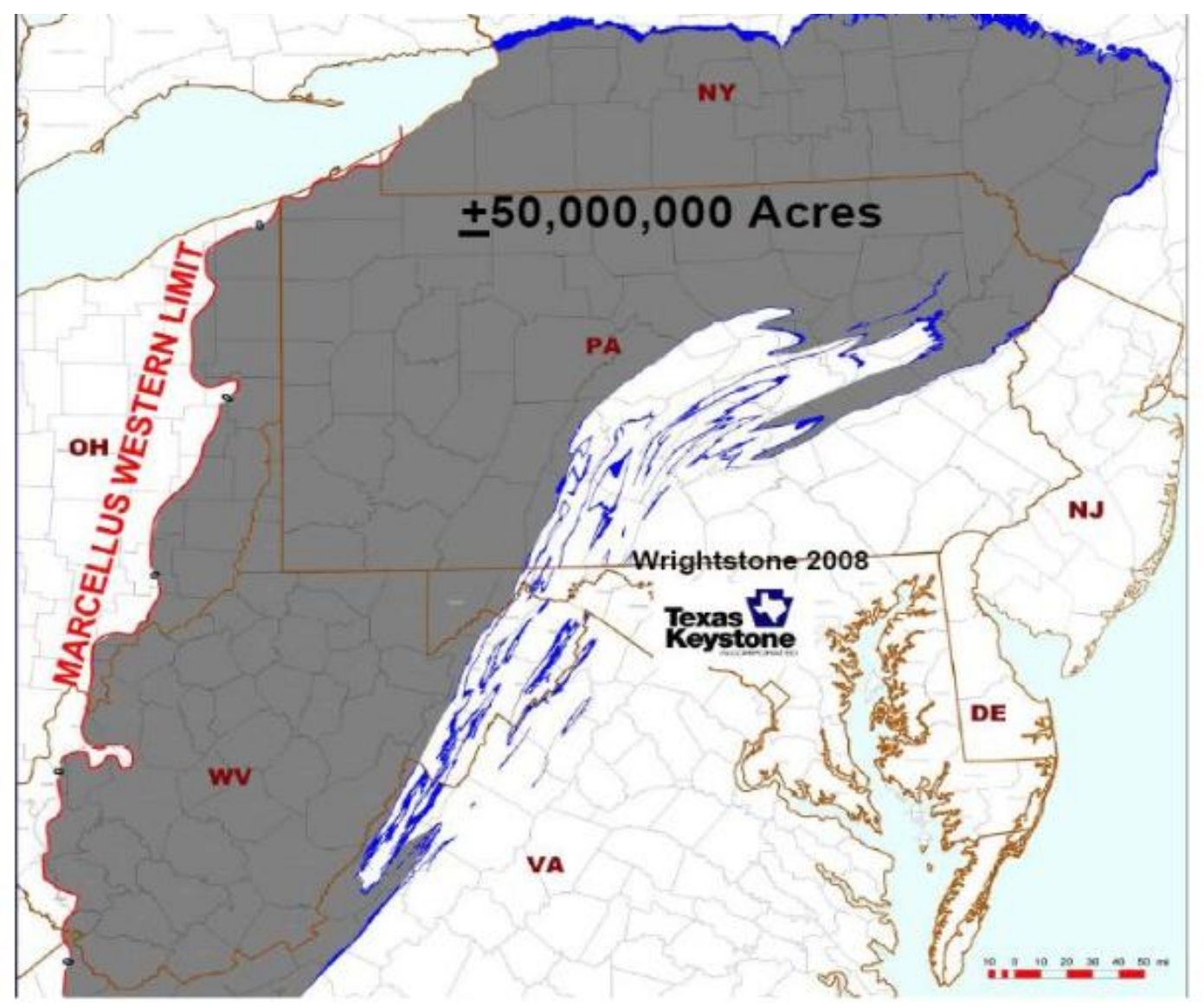

Figure 3: Marcellus Shale Gas play (EIA, 2011)

Other important geological factors to consider in the analysis of the Marcellus Shale are: Total organic carbon (TOC), Conodont color alteration index (CAI), vitrinite reflectance, depth of formation and the thickness of formation. These properties, in Table 1, are considered while deciding ideal drilling locations or other engineering operations to execute. 
Table 1: Comparison of data of shale formation in the U.S.

(J. Daniel Arthur et al, All Consulting 2008)

\begin{tabular}{|c|c|c|c|c|c|c|c|}
\hline Gas Shale Basin & Barnett & $\begin{array}{l}\text { Fayettevil } \\
\text { le }\end{array}$ & $\begin{array}{l}\text { Haynesvil } \\
\text { le }\end{array}$ & $\begin{array}{c}\text { Marcell } \\
\text { us }\end{array}$ & $\begin{array}{l}\text { Woodfo } \\
\text { rd }\end{array}$ & Antrim & $\begin{array}{l}\text { New } \\
\text { Albany }\end{array}$ \\
\hline $\begin{array}{l}\text { Estimated Basin } \\
\text { Area, square miles }\end{array}$ & 5,000 & 9,000 & 9,000 & 95,000 & 11,000 & 12,000 & 43,500 \\
\hline Depth, ft & 8,500 & 7,000 & 13,500 & 8,500 & 11,000 & 2,200 & 2,000 \\
\hline Thickness, ft & To 600 & To 200 & To 300 & To 200 & To 220 & To 120 & To 100 \\
\hline $\begin{array}{l}\text { Depth to Base of } \\
\text { Treatable Water\#, ft }\end{array}$ & 1200 & $\sim 500$ & $\sim 400$ & $\sim 850$ & $\sim 400$ & $\sim 300$ & $\sim 400$ \\
\hline $\begin{array}{l}\text { Rock Column } \\
\text { Thickness between } \\
\text { Top of Play and } \\
\text { Bottom of Treatable } \\
\text { Water, } \mathrm{ft}\end{array}$ & 7,300 & 6,500 & 13,100 & 7,650 & 10,600 & 1,900 & 1,600 \\
\hline $\begin{array}{l}\text { Total Organic Carbon, } \\
\%\end{array}$ & 4.5 & 9.8 & 4 & 12 & 14 & 20 & 25 \\
\hline Total Porosity, \% & $4-$ & 8 & 9 & 10 & 9 & 9 & 14 \\
\hline $\begin{array}{l}\text { Gas Content, } \\
\text { SCF/Ton }\end{array}$ & To 350 & To 220 & To 330 & To 100 & To 300 & To 100 & To 80 \\
\hline $\begin{array}{l}\text { Water Production, } \\
\text { Barrels water/day }\end{array}$ & $\mathrm{N} / \mathrm{A}$ & $\mathrm{N} / \mathrm{A}$ & $\mathrm{N} / \mathrm{A}$ & $N / A$ & $\mathrm{~N} / \mathrm{A}$ & $5-500$ & $5-500$ \\
\hline Well spacing, acres & $\begin{array}{c}60 \text { to } \\
160\end{array}$ & 80 to 160 & 40 to 560 & $\begin{array}{c}40 \text { to } \\
160\end{array}$ & 640 & $\begin{array}{c}40 \text { to } \\
160\end{array}$ & 80 \\
\hline $\begin{array}{l}\text { Original Gas-In-Place, } \\
\text { TCF }\end{array}$ & 327 & 52 & 717 & 1,500 & 23 & 76 & 160 \\
\hline $\begin{array}{l}\text { Technically } \\
\text { Recoverable } \\
\text { Resources }\end{array}$ & 44 & 41.6 & 251 & 262 & 11.4 & 20 & 19.2 \\
\hline
\end{tabular}

\subsection{Dual Porosity Reservoir - Dual Porosity Model}

The unconventional formations, such as Marcellus shale, are often characterized by dual porosity behavior. As demonstrated in the double-porosity model below, originally proposed by Warren and Root (1963), dual porosity reservoir is composed of matrix blocks with low permeability embedded in a network of interconnected fractures. 


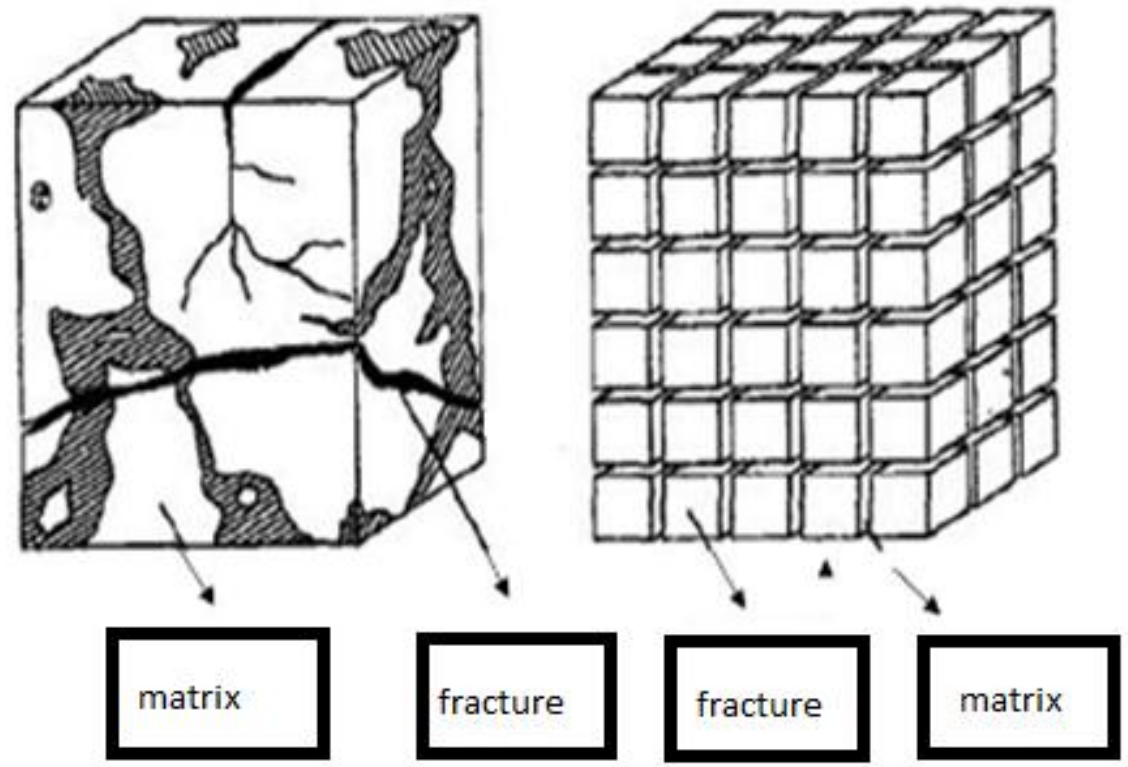

Figure 4: Classic double-porosity model (Warren \& Root, 1963)

According to Cong Wang (2014), the flow and transport of gas in the dual porosity formations "occurs only through the fracture system, conceptualized only as an effective continuum". In other words, the model is not taking into account the matrix within the spatially well-distributed blocks of the whole matrix. For the purpose of a modeling analysis for instance, the dual porosity reservoir model is assumed to be a homogeneous reservoir.

\subsection{Horizontal Drilling:}

Horizontal drilling is one of the techniques that have made low permeability shale formation economically productive. Horizontal drilling consists of drilling well horizontally at the depth of formation pay zones. 

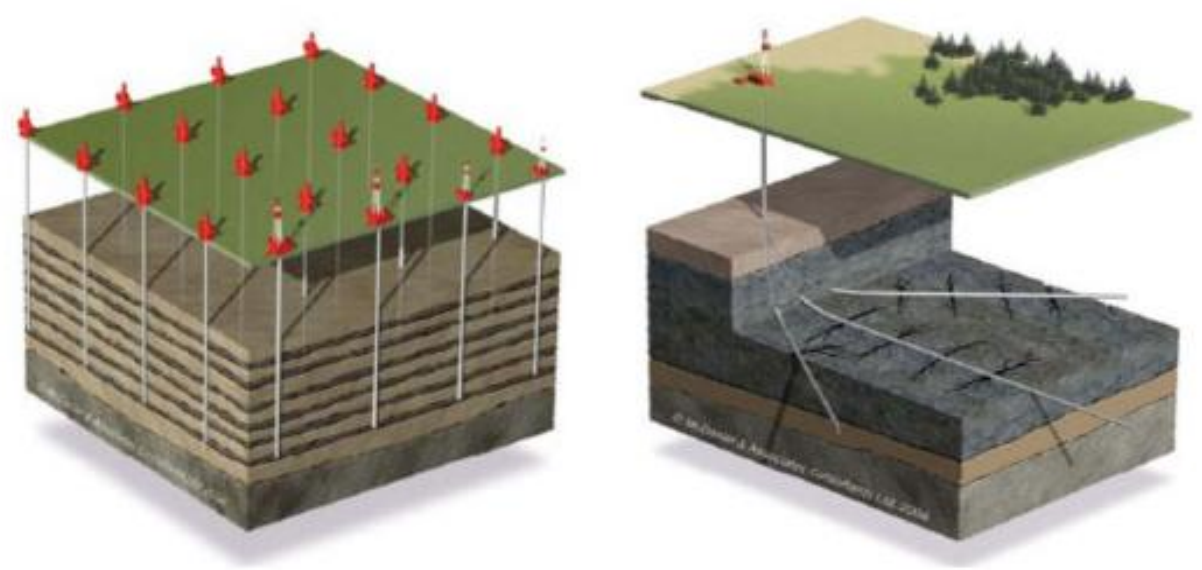

Figure 5: Tradition wells vs. Horizontal drilling (ANGA, 2014)

Horizontal drilling is very popular in Marcellus Shale formation. Drilling a well horizontally will target multiple reservoir sweet spots, where the average of length of the lateral in the Marcellus around $4000 \mathrm{ft}$., though it has been reported wells to have been drilled around 12,000 ft. lateral section (Belvalkar, R. \& Oyewole, S.2010). Another prominent advantage of horizontal drilling is the reduction of surface footprint since it circumvents drilling multiples vertical wells as seen in Figure 5 (Belvalkar, R. \& Oyewole, S., 2010). Additionally, pad drilling and rig mobility are other tools assembled to further reduce permanent rigs construction as shown in Figure 6 (EIA, 2012).
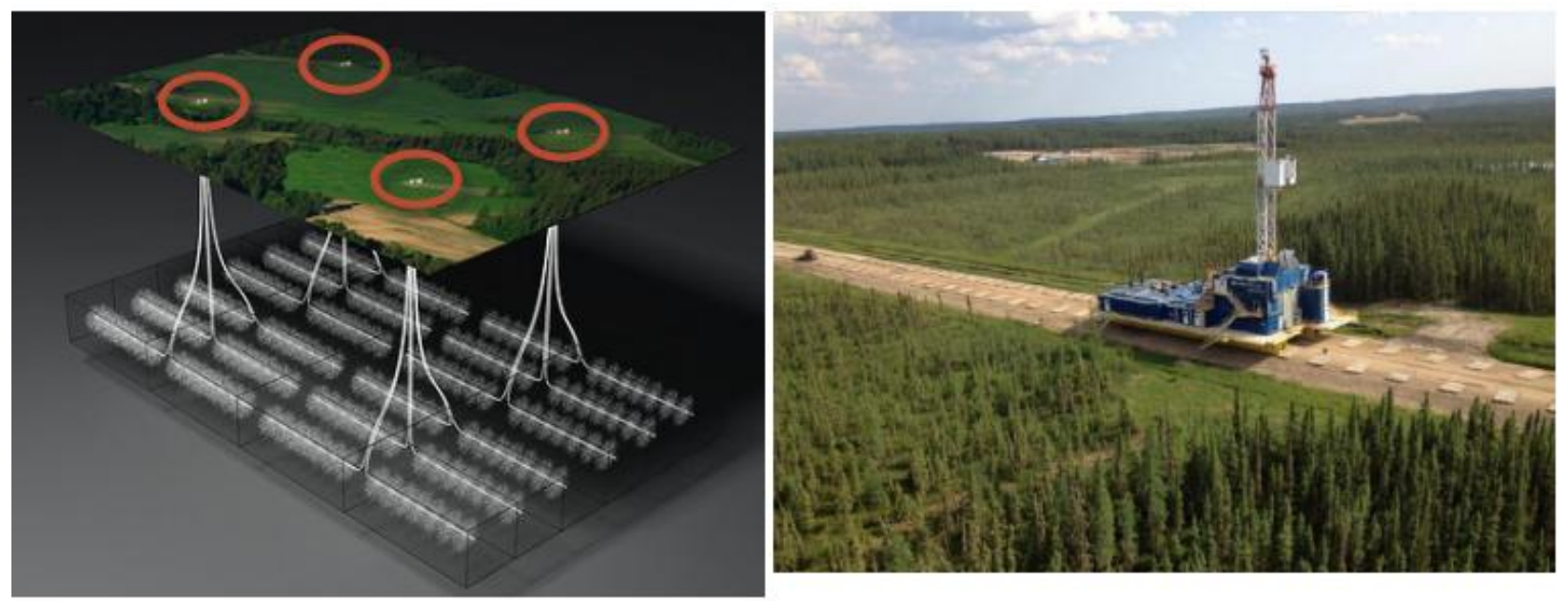

Figure 6: Pad drilling and rig mobility lead to more efficient drilling (EIA, 2012) 


\subsection{Hydraulic fracturing:}

Hydraulic fracturing is an operation performed after drilling to increase well productivity by making fractures in the formation which increases the drainage area of the reservoir (Belvalkar, R. \& Oyewole, S., 2010). All shale gas reservoirs require fracture stimulation to connect the natural fractures network to the wellbore in order to get optimal and economical production rates (Joshi, S.D., pp 92).

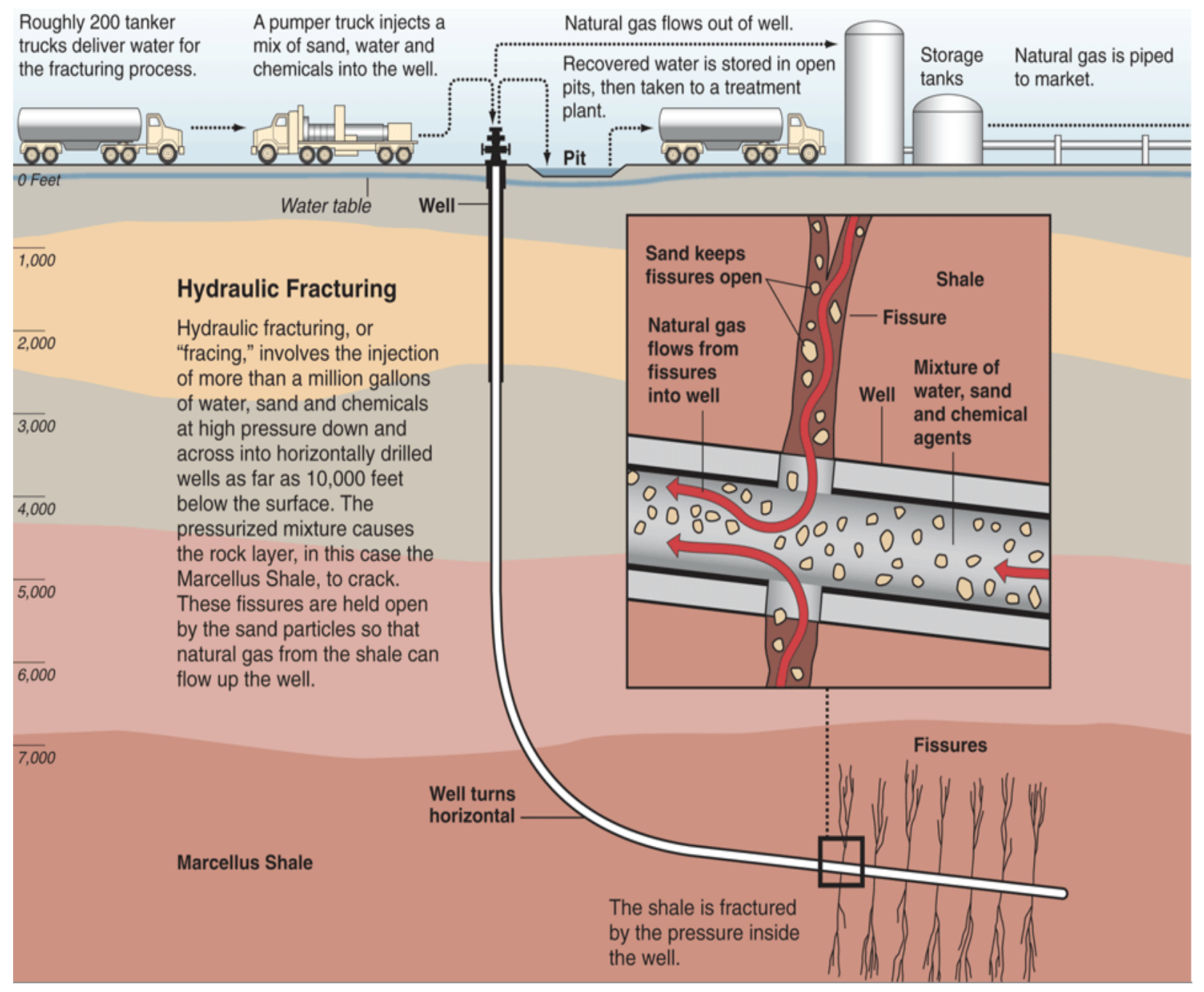

Figure 7: Marcellus Shale Hydraulic Fracturing (Hydraulic Fracturing, 2011)

In spite of media controversy surrounding this issue, hydraulic fracturing is not new. It was first designed for a well treatment in the Hugoton field of Kansas in 1946 to stimulate its production (Economides \& Martin, pp. 93). Hydraulic fracturing can be considered a historic tool for U.S' 
ambitious effort to rely on its own natural resources by not only rendering production of unconventional reservoirs possible and more economical, but by restoring production recovery from old/abandoned wells. As Economides states in his books: “...fracturing can be thought as a process that minimizes the energy required for the gas to reach the wellbore..." (Economides \& Martin, pp. 15). The benefits that can be reaped from hydraulic fracturing in the management and development of a reservoir are:

1- To increase the flow rate of hydrocarbons at the surface

2- To prolong a reservoir efficient flow to the wellbore by reducing its natural/normal energy (i.e. pressure) necessary to achieve profitable production, henceforth to greatly increase its recovery factor.

3- To decrease the pressure drop

But ultimately, hydraulic fracturing is a process used in Marcellus shale to increase "shale gas" production by creating or restoring small fractures in a formation with use of fluids (water mostly) and proppant (sand in most cases), as shown in Figure 7, to increase the drainage area. These fractures are analyzed before and after the process to determine the efficiency of a hydraulic fracturing job.

\subsubsection{Fracture Orientation:}

Hydraulic fractures are formed in the direction perpendicular to the least stress (Economides \& Martin, pp. 119). At depth of less than $2000 \mathrm{ft}$., horizontal fractures will occur after a hydraulic fracturing job because the earth's overburden at these depths provides the least principal stress. However, at depth over $2000 \mathrm{ft}$., the overburden stress (also called vertical stress) increases by $1 \mathrm{psi} / \mathrm{ft}$. and becomes the dominant stress. As stated above and illustrated in Figure 8, the least stress being always perpendicular to hydraulic fractures, these last ones will be in vertical direction at depth above $2000 \mathrm{ft}$. 


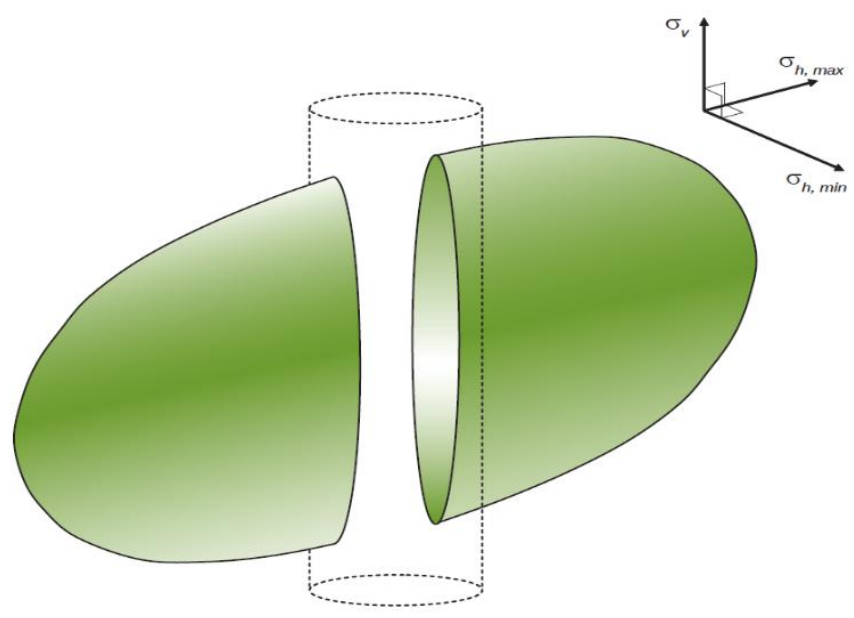

$\sigma_{\mathrm{h}, \min }=$ the minimum horizontal stress (in-situ stres

$\sigma_{\mathrm{h}, \max }=$ the maximum horizontal stress

$\sigma_{\mathrm{v}} \quad=$ the vertical stress

Figure 8: Fracture propagation perpendicular to the minimum horizontal stress (Economides \& Martin, pp. 122)

\subsubsection{Fracture Length/Height}

In general, the length and height of a hydraulic-fracture is controlled by the type of zone the formation to be hydraulic-fractured is confined, as well as the volume, rate, and pressure of the fluid to be pumped for the fracture job. It should be noted that natural fractures or faults in the formation also influence the length and height of the hydraulic-fracture job.

Prior to any hydraulic-fracturing job, design engineers must run model to determine the optimum fracture treatment. They use data from well test to make their design; fracture propagation models are generated after running computer program. There are two widely used models and a third not so used illustrated in Figure 9:

- PKN geometry model as illustrated in the figure below is used when fracture height is fixed, and the width is proportional to fracture height.

- KGD geometry model is used when the fracture height is fixed, the width is proportional to fracture length.

- With higher computational software, 3D fracture design can now be generated. 


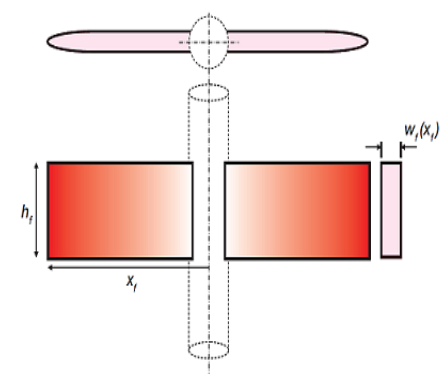

(1)

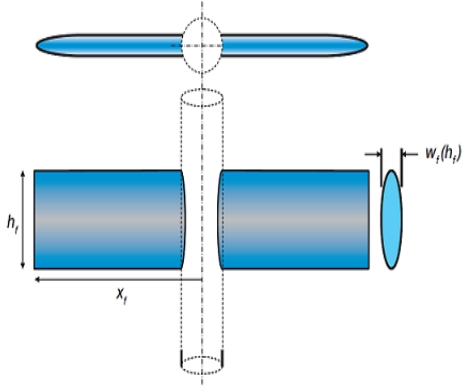

(2)

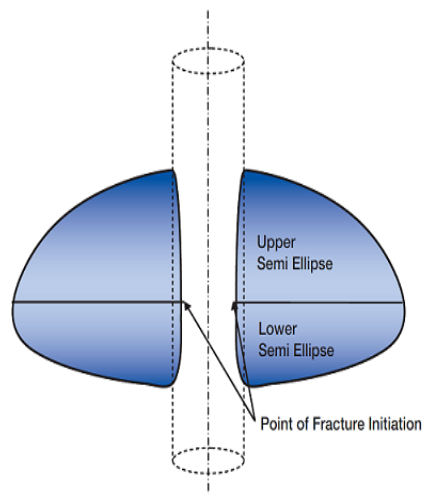

(3)

Figure 9: (1) PKN fracture Geometry; (2) KGD fracture Geometry; (3) Lumped-parameter

\section{3-D modeling showing two semi-ellipses (Economides \& Martin, pp. 125)}

Factors such as fracture toughness, Young's modulus, and fracture fluid viscosity are also used to generate hydraulic fracture treatment models.

\subsubsection{Dimensionless Fracture Conductivity:}

Dimensionless fracture conductivity is an important parameter in the design of hydraulic-fracture treatments. By Pearson's definition, dimensionless fracture conductivity is "a key parameter in well stimulation that compares the capacity of the fracture to transmit fluids down the fracture and into the wellbore, with the ability of the formation to deliver fluid into the fracture" (Pearson, 2001). So during designs, obtaining accurate dimensionless fracture conductivity when designing the hydraulic fractures of wells to be fractured will improve productivity.

Fracture conductivity is the product of fracture permeability and propped fracture width left after the fracture has closed. Fracture conductivity is defined as:

Where:

$$
C_{f d}=\frac{k_{f} w}{k x_{f}}
$$

$\mathbf{C}_{\mathbf{f d}}$-dimensionless fracture conductivity,

$\mathbf{k}_{\mathbf{f}} \mathbf{W}$ - fracture conductivity, $\mathbf{x}_{\mathbf{f}}$-fracture length

$\mathbf{k}_{\mathbf{f}}$-proppant permeability ,

$\mathbf{w}_{\mathbf{f}}$ - fracture width 


\subsection{Multi-lateral horizontal wells}

Horizontal wells as well as Multi-Lateral horizontal wells is an engineering technology that is gaining enormous popularity especially in low-permeability unconventional reservoirs, as it offers many benefits to operators such as greater exposure to pay zone (more production), reduction in platform cost, lessening environmental concerns, primary target area in the reservoir drilled only once etc. (Crouse, 2014); all for the primary purpose of maintaining and increasing productivity.

A multi-lateral horizontal well is defined as a well that has more than one horizontal or near horizontal lateral well drilled from a single site and connected back to a single wellbore (Crouse, 2014). There are many configurations that have been created already as illustrated in Figure 10.

Although there are ongoing efforts in research and development, this technology presents many risks in the development of a reservoir, as it has yet to be mastered: the loss of production and reserves if there are cross-flows or interference from one lateral to another; additional well control precautions and measures need to be taken as impairment and cleanup of individual laterals or branches is still an issue not resolved in the industry; pressure loss is important issue as drilling a new lateral or branch in potentially unsure area in the reservoir can have a severe impact on production (Crouse, 2014).

\subsubsection{Drainage area:}

Multi-lateral well concept strategies were introduced to increase the total drainage area especially in low permeability formations with the purpose of increasing their productivity. Production performance of horizontal well - let alone multi-horizontal wells - is challenging to effectively evaluate because horizontal well exact producing length (i.e. drainage area) may not be well known "unless production logging has been used to measure the rate at which fluid enters the hole at different locations" (Aminian, 2013).

As a rule of thumb, a 1000-ft-long horizontal well can drain twice the area of a vertical well while a 2000-ft-long well can drain three times the area of a vertical well in a given time as shown in Figure 11 
(1) and (2). Thus, it is important to use larger well spacing for horizontal well development than that used for vertical well development (Joshi, S.D., 1991).

More research such as reservoir characterization are being applied to assessing reservoir quality and targeting formation sweet spots which in turn will optimize well placement (and spacing) and hydraulic fracturing, and ultimately hydrocarbons recovery (Carpenter, pp. 116).

\subsubsection{Well-Spacing and Well-Interference:}

Optimum well spacing is defined by Van Winegen as the "density of wells that will result in the greatest ultimate profit to the operator" (Aminian, 1985). According to Dr. Aminian et al., the number of wells drilled in a reservoir increases the total rate of its production; however, there exists a specific number that when determined, can result to optimum recovery, or else, the inter-well interference of more wells drilled above the required number can significantly reduce the total rate of production(Aminian, 1985). The same can be said about multi-lateral wells and to a greater extend, the spacing of these wells must be seriously deliberated. Well interference is noticeable when the group of wells is placed in the small drainage area of a reservoir (Aminian, 1985). A reservoir (with multi-lateral wells) which has been developed with a well spacing that does not have well interference issues has a greater chance of maximum recovery (Fanchi, pp. 82). 


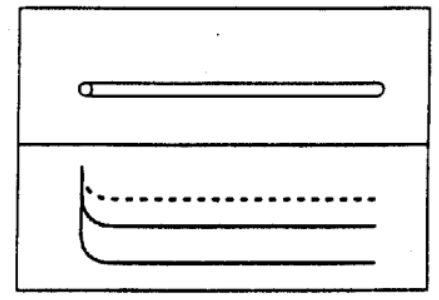

Stacked Dual-Lateral and TriLateral

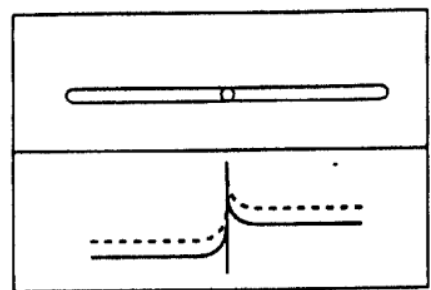

Dual-Opposed Lateral and Stacked/Opposed Quadrilateral

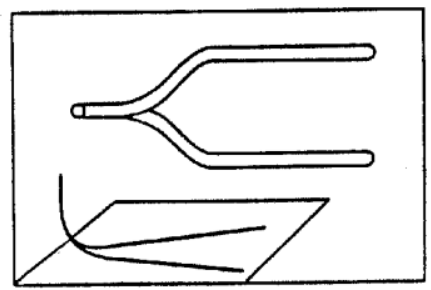

Planar Dual-Lateral

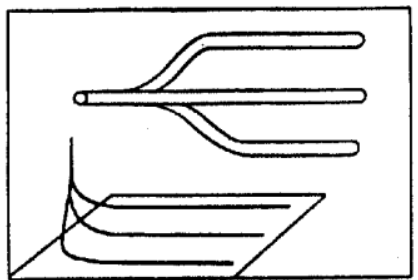

Planar Tri-lateral

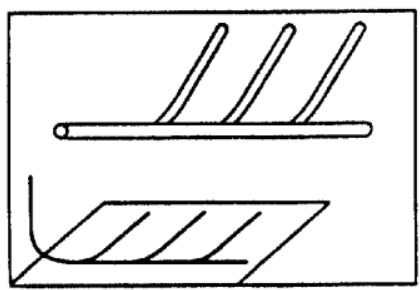

Planar Offset Quadrilateral

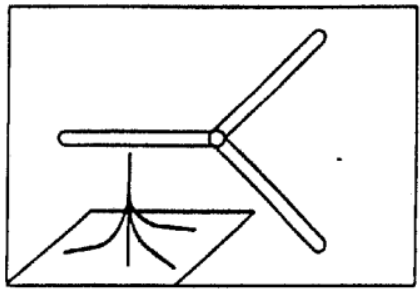

Radial Tri-Lateral Extending From Primary Vertical Wellbore

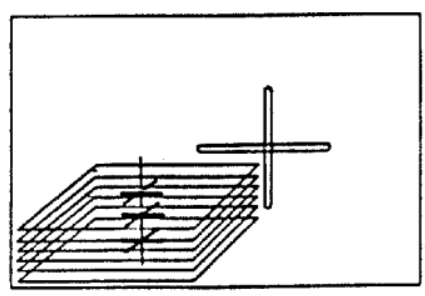

Stacked Radial Quadrilaterals

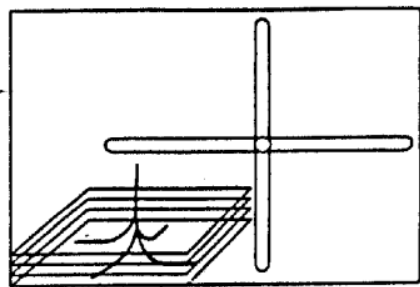

Radial Quadrilateral

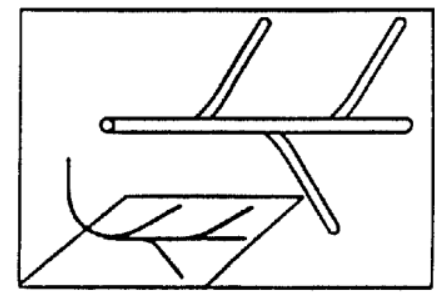

Planar Opposed Quadrilateral

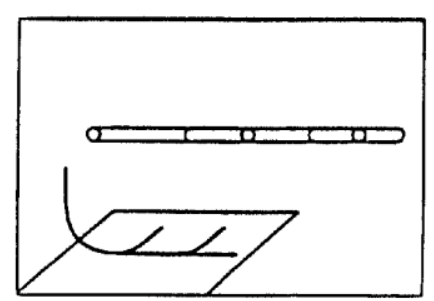

Stacked/Inclined Tri-lateral

Figure 10: Figures of well Strategies for Multi-lateral wells (Phillip C. Crouse, P.E., US DOE, 2014) 


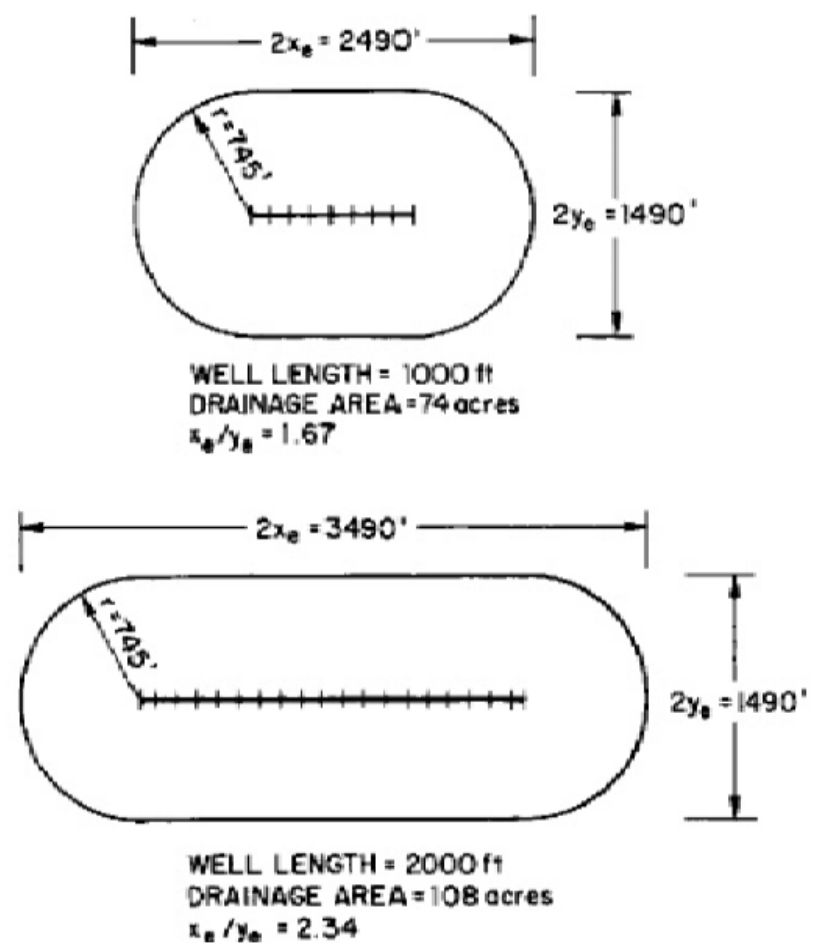

(1)

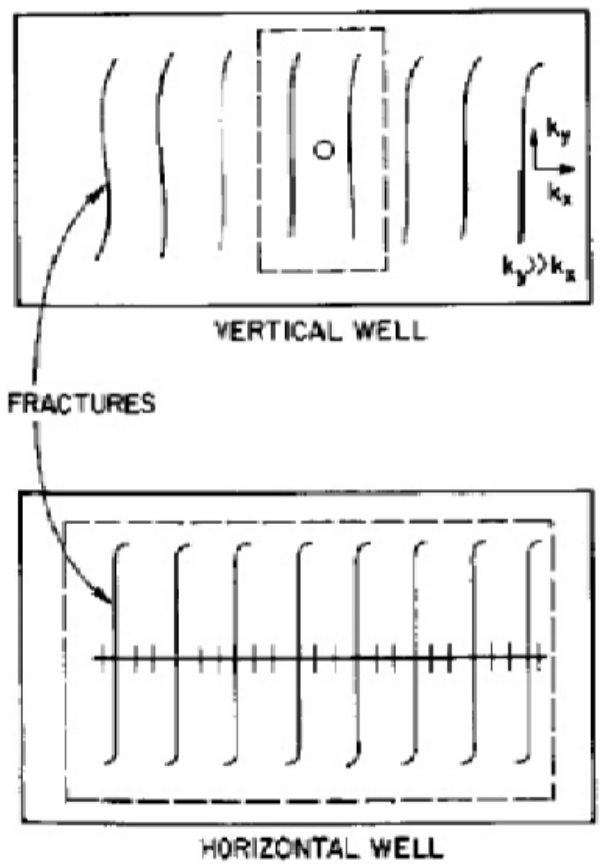

(2)

Figure 11: (1) Drainage areas of $1000 \mathrm{ft}$. and $2000 \mathrm{ft}$; (2) Drainage Areas of Horizontal and Vertical wells in a Fractured Reservoir (Joshi, 1991) 


\section{OBJECTIVES AND METHODOLOGY}

\subsection{Objectives}

The main goal of this research study was to analyze and understand the impact of spacing of hydraulically fractured multi-horizontal laterals on their production performance in low-permeability formations such as Marcellus Shale. This was completed by achieving the following objectives:

- Develop a base model that can accurately simulates the production profiles of hydraulic fractured multi-lateral horizontal wells.

- Investigate the impact of horizontal well spacing on the gas recovery for hydraulic fractured horizontal wells, for the ultimate purpose of maximizing recovery.

\subsection{Methodology:}

Models parameters were based in concordance with average properties of Marcellus shale formation and also common hydraulic fractures properties used during field operations. The ECLIPSE simulator software (by Schlumberger) was used to model multi-layer dual porosity reservoirs, with adsorbed gas component, to simulate the production profiles for a period of 30 years.

\subsubsection{Objective 1:}

The first objective of this research was to develop a base model to predict the production performance of hydraulically fractured horizontal laterals. To accomplish this, the Eclipse simulator software (by Schlumberger) was used to simulate the production profiles using the base model parameters listed in Table 2. The base model developed with our simulator software was a rectangular drainage area of 8000 ft. $\times 4000 \mathrm{ft}$. with two lateral horizontal wells each of $6000 \mathrm{ft}$. long and 25 hydraulic fracture stages. The parameters considered to evaluate the base model included the dimensions of the drainage area, the number of wells and distance between the wells, and the hydraulic fractures properties such as width and half-length. Two production profiles were simulated for this study after obtaining our base model: one 
characterized with hydraulic fractures half-length of $500 \mathrm{ft}$., and the other characterized with hydraulic fractures half-length of $300 \mathrm{ft}$.

It should be noted that prior to selecting our base model drainage area for this research study, various drainage areas, listed in Table 3, all containing a single horizontal lateral well, were modeled to simulate their production profiles. The model with drainage area of $4000 \mathrm{ft} . \times 2000 \mathrm{ft}$. and 13-staged hydraulic fractures was selected after careful post-analysis of the others and its production profiles. This model (4000 ft. $\times 2000 \mathrm{ft}$.) was then doubled in size and in number of hydraulic fractures to obtain our base model.

\subsubsection{Objective Two:}

The second objective of our research was to analyze the production profiles of the hydraulic fractured multi-lateral horizontal wells relative to their spacing. The two simulated models from the base model, a drainage area $8000 \mathrm{ft}$. $\times 4000 \mathrm{ft}$. containing two $6000 \mathrm{ft}$. horizontal wells with 25 stage - hydraulic fractured spaced $250 \mathrm{ft}$. from each other with a half-length of $500 \mathrm{ft}$., and a drainage area L8000 ft. $\times$ w4000 ft. containing 25 stage -hydraulic fractured spaced $250 \mathrm{ft}$. each with a half-length of $300 \mathrm{ft}$., were used to generate various productions results in order to analyze and evaluate their profiles for our research study. Table 4 summarizes the different simulation runs for the second objective of our research, which is to investigate well spacing. 
Table 2: Models Parameters used to develop base model

\begin{tabular}{|c|c|}
\hline \multicolumn{2}{|c|}{ Reservoir Parameters } \\
\hline Thickness, ft. & 75 \\
\hline Depth, ft & 7000 \\
\hline \multicolumn{2}{|c|}{ Rock Properties } \\
\hline Fissure Spacing, $\sigma, 1 / \mathrm{ft}^{2}$ & 0.0073 \\
\hline Compressibility, $1 /$ psia & $1 \mathrm{E}-6$ \\
\hline \multicolumn{2}{|c|}{ Initial Conditions } \\
\hline Initial Reservoir Pressure, Psia & 3000 \\
\hline Water Saturation, fraction & 0.15 \\
\hline \multicolumn{2}{|c|}{ Natural Fracture Properties } \\
\hline Porosity Type & Dual \\
\hline Fissure Porosity, frac. & 0.005 \\
\hline Matrix Porosity, frac. & 0.05 \\
\hline Fissure perm, i, j, k, md & $0.002,0.002,0.0002 / 0.004,0.004,0.0004$ \\
\hline Matrix perm, i, j, k, md & $0.0004,0.0004,0.00004 / 0.0008,0.0008,0.00008$ \\
\hline Fissure Spacing, $\sigma, 1 / \mathrm{ft}^{2}$ & 0.0073 \\
\hline \multicolumn{2}{|c|}{ Hydraulic Fractures Properties } \\
\hline Half-length, ft. & Varies $(300,500,600)$ \\
\hline Width, in & Varies $(0.005,0.01,0.02)$ \\
\hline Permeability, md & 20000 \\
\hline Porosity, fraction & 0.2 \\
\hline Top Fracture, $\mathrm{ft}$ & 7000 \\
\hline Bottom of the fracture, $\mathrm{ft}$ & 7075 \\
\hline \multicolumn{2}{|c|}{ Well Production Control } \\
\hline Pwf, psia & 500 \\
\hline \multicolumn{2}{|c|}{ Fluid Properties } \\
\hline Standard Pressure, psia & 14.7 \\
\hline Standard Temperature, OF & 60 \\
\hline Reference Temperature, oF & 120 \\
\hline \multicolumn{2}{|r|}{ Adsorption } \\
\hline Diffusion Coefficient, $\mathrm{ft}^{2} /$ day & 1 \\
\hline Sorption Time, day & 62 \\
\hline Langmuir Pressure, psia & 635 \\
\hline Langmuir Concentration, MSCF/ton & 0.08899 \\
\hline
\end{tabular}


Table 3: Summary of simulation run cases to obtain a model for developing the base model

\begin{tabular}{|c|c|c|}
\hline Cases for developing/obtaining our base model & Runs & Parameters Varied \\
\hline \multirow{6}{*}{$\begin{array}{c}\text { (1) } 3000 \text { ' Lateral Well } \\
\text { with drainage area with } \\
\text { Length } 5000 \mathrm{ft} \text {. \& half-length } 500 \mathrm{ft} \text {. }\end{array}$} & Run 1 & w1000' (7-frac) \\
\hline & Run 2 & w2000' (7-frac) \\
\hline & Run 3 & w4000' (7-frac) \\
\hline & Run 4 & w1000' (13-frac) \\
\hline & Run 5 & w2000' (13-frac) \\
\hline & Run 6 & w4000' (13-frac) \\
\hline \multirow{6}{*}{$\begin{array}{c}\text { (1) } 3000 \text { ' Lateral Well } \\
\text { with drainage area with } \\
\text { width } 2000 \mathrm{ft} \text {. \& half-length } 500 \mathrm{ft} \text {. }\end{array}$} & Run 7 & L3500' (7-frac) \\
\hline & Run 8 & L4000' (7-frac) \\
\hline & Run 9 & L6000' (7-frac) \\
\hline & Run 10 & L3500' (13-frac) \\
\hline & Run 11 & L4000' (13-frac) \\
\hline & Run 12 & L6000' (13-frac) \\
\hline \multirow{6}{*}{$\begin{array}{c}\text { (1) } 3000 \text { ' Lateral Well \& } \\
\text { drainage area of length L4000 ft } \\
\text { \& fracture Half-Length } 300 \mathrm{ft} .\end{array}$} & Run 13 & w1000 (7-frac) \\
\hline & Run 14 & w2000 (7-frac) \\
\hline & Run 15 & w4000 (7-frac) \\
\hline & Run 16 & w1000 (13-frac) \\
\hline & Run 17 & w2000 (13-frac) \\
\hline & Run 18 & w4000 (13-frac) \\
\hline \multirow{6}{*}{$\begin{array}{c}\text { (1) } 3000 \text { ' Lateral Well \& } \\
\text { drainage area of length L4000 ft } \\
\text { Half-Length } 600 \mathrm{ft} .\end{array}$} & Run 19 & w1000 (7-frac) \\
\hline & Run 20 & w2000 (7-frac) \\
\hline & Run 21 & w4000 (7-frac) \\
\hline & Run 22 & w1000 (13-frac) \\
\hline & Run 23 & w2000 (13-frac) \\
\hline & Run 24 & w4000 (13-frac) \\
\hline \multirow{2}{*}{$\begin{array}{l}\text { (1) } 6000 \text { ' lateral well w/ } 25 \text { frac. Width } 0.01 \text { in. } \\
\text { of Half-Length } 500 \mathrm{ft} \text { of frac. }\end{array}$} & Run 25 & L8000Xw4000 \\
\hline & Run 26 & L8000Xw2000 \\
\hline \multirow{2}{*}{$\begin{array}{l}\text { (1) } 6000 \text { ' lateral well w/ } 25 \text { frac. Width } 0.01 \text { in. } \\
\text { of Half-Length } 300 \mathrm{ft} \text {. of frac. }\end{array}$} & Run 27 & L8000Xw4000 \\
\hline & Run 28 & L8000Xw2000 \\
\hline
\end{tabular}


Table 4: Summary of simulation to investigate horizontal investigate well spacing

\begin{tabular}{|c|c|c|}
\hline Cases For Well Spacing Investigation & Runs & Parameters Varied \\
\hline \multirow{3}{*}{$\begin{array}{l}\text { (2) } 6000 \text { lateral wells } 18000 X w 4000 \mathrm{w} / \\
50 \text { frac. width } 0.01 \mathrm{in.} \& \text { half-length } 500 \mathrm{ft} \text {. }\end{array}$} & Run 29 & 2000' Apart \\
\hline & Run 30 & 1000' Apart \\
\hline & Run 31 & 2500' Apart \\
\hline \multirow{7}{*}{$\begin{array}{l}\text { (2) } 6000 \text { ' lateral wells } \\
\text { L8000Xw4000 w/ } 50 \text { frac. width } 0.01 \mathrm{in} \text {. } \\
\text { of half-length } 300 \mathrm{ft} \text {. }\end{array}$} & Run 32 & 2000 ' Apart \\
\hline & Run 33 & 2500' Apart \\
\hline & Run 34 & 1800' Apart \\
\hline & Run 35 & 1600' Apart \\
\hline & Run 36 & 1000' Apart \\
\hline & Run 37 & 1200' Apart \\
\hline & Run 38 & 600' Apart \\
\hline \multirow{3}{*}{$\begin{array}{l}\text { (2) } 6000 \text { ' lateral wells } \\
\text { L8000Xw4000 w/ } 50 \text { frac. width } 0.02 \mathrm{in.} \\
\text { of half-length } 500 \mathrm{ft} \text {. }\end{array}$} & Run 39 & 2000' Apart \\
\hline & Run 40 & 2500' Apart \\
\hline & Run 41 & 1800' Apart \\
\hline \multirow{3}{*}{$\begin{array}{l}\text { (2) } 6000 \text { ' lateral wells } \\
\text { L8000Xw4000 w/ } 50 \text { frac. width } 0.02 \mathrm{in.} \\
\text { of half-length } 300 \mathrm{ft} \text {. }\end{array}$} & Run 42 & 2000' Apart \\
\hline & Run 43 & 2500' Apart \\
\hline & Run 44 & 1800' Apart \\
\hline \multirow{3}{*}{$\begin{array}{l}\text { (2) } 6000 \text { ' lateral wells } \\
\text { L8000Xw4000 w/ } 50 \mathrm{frac} \text {. width } 0.005 \mathrm{in} \text {. } \\
\text { of half-length } 300 \mathrm{ft} \text {. }\end{array}$} & Run 45 & 2000' Apart \\
\hline & Run 46 & 2500' Apart \\
\hline & Run 47 & 1800' Apart \\
\hline \multirow{4}{*}{$\begin{array}{c}\text { (2) } 6000 \text { ' lateral wells w/ doubled Matrix } \\
\text { Perm. to } 0.004,0.004,0.0004(i, j, k) \\
\text { with frac. Half-length } 500 \mathrm{ft} \text {. }\end{array}$} & Run 48 & 2000' Apart \\
\hline & Run 49 & 2500' Apart \\
\hline & Run 50 & 1800' Apart \\
\hline & Run 51 & 2000' Apart \\
\hline \multirow{3}{*}{$\begin{array}{l}\text { (2) } 6000 \text { ' lateral wells w/ doubled Matrix } \\
\text { Perm. to } 0.004,0.004,0.0004(i, j, k) \\
\text { with frac. Half-length } 300 \mathrm{ft} \text {. }\end{array}$} & Run 52 & 2500' Apart \\
\hline & Run 53 & 1800' Apart \\
\hline & Run 54 & $600^{\prime}$ Apart \\
\hline
\end{tabular}




\section{RESULTS AND DISCUSSIONS}

After methodologically completing simulation runs and generating the production profiles, the results were analyzed and discussed in the following sections.

\subsection{Objective 1:}

The base model used for most simulation runs was a rectangular drainage area of $8000 \mathrm{ft} . \times 4000 \mathrm{ft}$. with two lateral horizontal wells each $6000 \mathrm{ft}$. long and 25 hydraulic fractures $(250 \mathrm{ft}$. hydraulic fractures spacing) as illustrated in Figure 12; although in some instances a drainage area of $8000 \mathrm{ft} . \times 2000 \mathrm{ft}$. was used to analyze our findings.

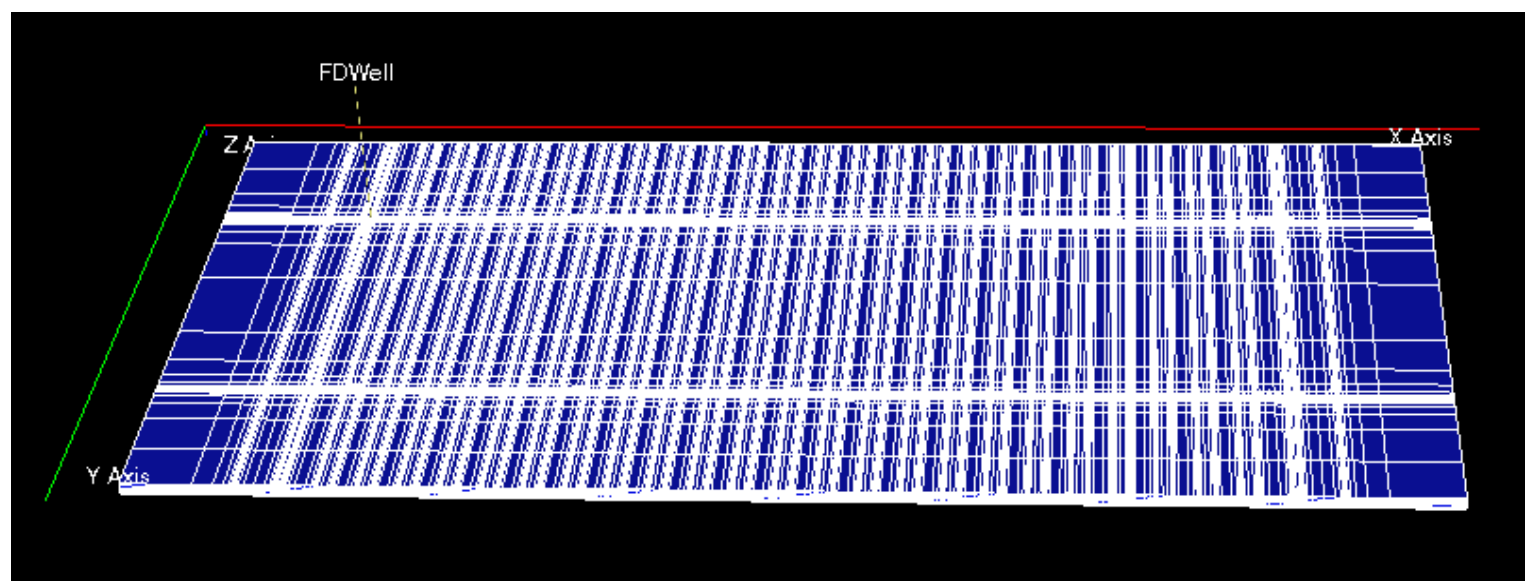

Figure 12: Generated base model $8000 \mathrm{ft} . \times 4000 \mathrm{ft}$. (by Eclipse) containing two horizontal wells with 25 hydraulic fractures each.

As Figures A.1, A.2, A.3, A.4, A.5, A.6, A.7, and A.8 in Appendix A show models with single lateral horizontal well as in Run 1 through Run 24 were simulated and analyzed to estimate the base model dimensions. The production profiles of the drainage area of $4000 \mathrm{ft} . \times 2000 \mathrm{ft}$. with 13 hydraulic fractures (250 ft. hydraulic fractures spacing), which is illustrated in Figure A.4 in Appendix A and is highlighted in Table 3 as Run 11, is the one that was doubled in size to obtain the base model.

Figure A.9 compares the cumulative production results of Run 25 and Run 26, both with a $6000 \mathrm{ft}$. long hydraulically fractured horizontal lateral with half-length of $500 \mathrm{ft}$. and width of $0.01 \mathrm{in}$., and $250 \mathrm{ft}$. 
space between each hydraulic fracture stage, to obtain our base model. As it can be observed, though the drainage areas greatly vary, the cumulative production results of each well are almost identical up to 15 years of production until they start vary. This indicates that a single well may not be enough to economically maximize the gas recovery of the base model with drainage area of $8000 \mathrm{ft} . \times 4000 \mathrm{ft}$. This demonstrates that two wells are needed to drain an area of $8000 \mathrm{ft} . \times 4000 \mathrm{ft}$. The same results, illustrated in Figure A.10, are obtained in Run 27 and Run 28 having a hydraulically fractured horizontal lateral with half-length of $300 \mathrm{ft}$.

Therefore, the base model is of a drainage area $8000 \mathrm{ft} . \times 4000 \mathrm{ft}$. having two horizontal wells, each $6000 \mathrm{ft}$. long and 25 hydraulically fractured stages.

\subsection{Objective 2:}

To better understand the impact of well spacing on the production performance of base models, the two hydraulically fractured horizontal wells were simulated using various distances between them to identify the spacing that can provide maximum recovery in a drainage area of $8000 \mathrm{ft} . \times 4000 \mathrm{ft}$.

Figure B.1 below compares the production results of Run 29, Run 30, and Run 31. As it is observed, the model in Run 29 has a better recovery than the other ones in Run 30 and Run 31.This means that if each horizontal well is considered draining in an $8000 \mathrm{ft}$. $\times 2000 \mathrm{ft}$. area, they have a better recovery when they are placed in the middle of the field. Additionally from the production profiles, when the horizontal wells are drilled closer to each other, looking at the wells $1000 \mathrm{ft}$. apart in Run 30, the recovery decreases considerably compared to the others (Run 29 and Run 31). Finally, as the lateral horizontal wells are drilled closer to the longitudinal boundaries, the recovery sensibly decreases as it is the case in Run 31 . 


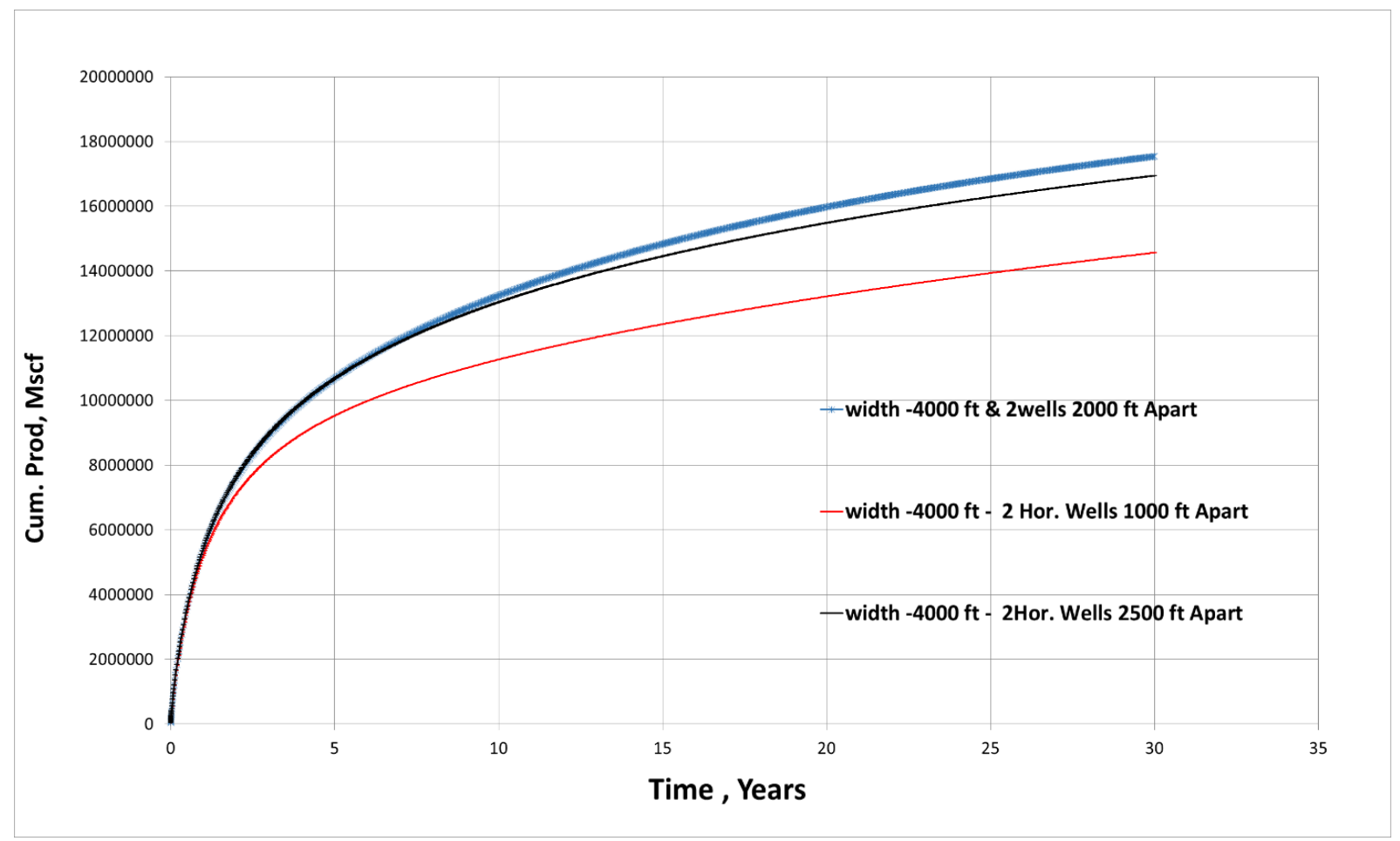

Figure B.1: Cumulative Production results vs. Time of hydraulically fractured horizontal lateral(s) - Results of Run 29, 30, and 31 in Table 4.

Interestingly in Figure B.2, when horizontal laterals hydraulic fractures' half-length decreases to $300 \mathrm{ft}$, again as in Run 32, a $2000 \mathrm{ft}$. distance between the two horizontal wells still gives the best recovery; the other production profiles of wells in Run 33, Run 34, and Run 35 have almost identical production results. As the space between the wells gradually further decreases, as in Run 36, Run 37, and Run 38, their production rates respectively and steadily decrease. This indicates that within the realm of possibility, the more the drainage areas of horizontal wells interfere with each other, the more the production decreases. So after lowering the half-length of the fractures, there exists a space between the horizontal wells where the recovery is not impacted as much by the change in that distance as seen on Figure B.1. 


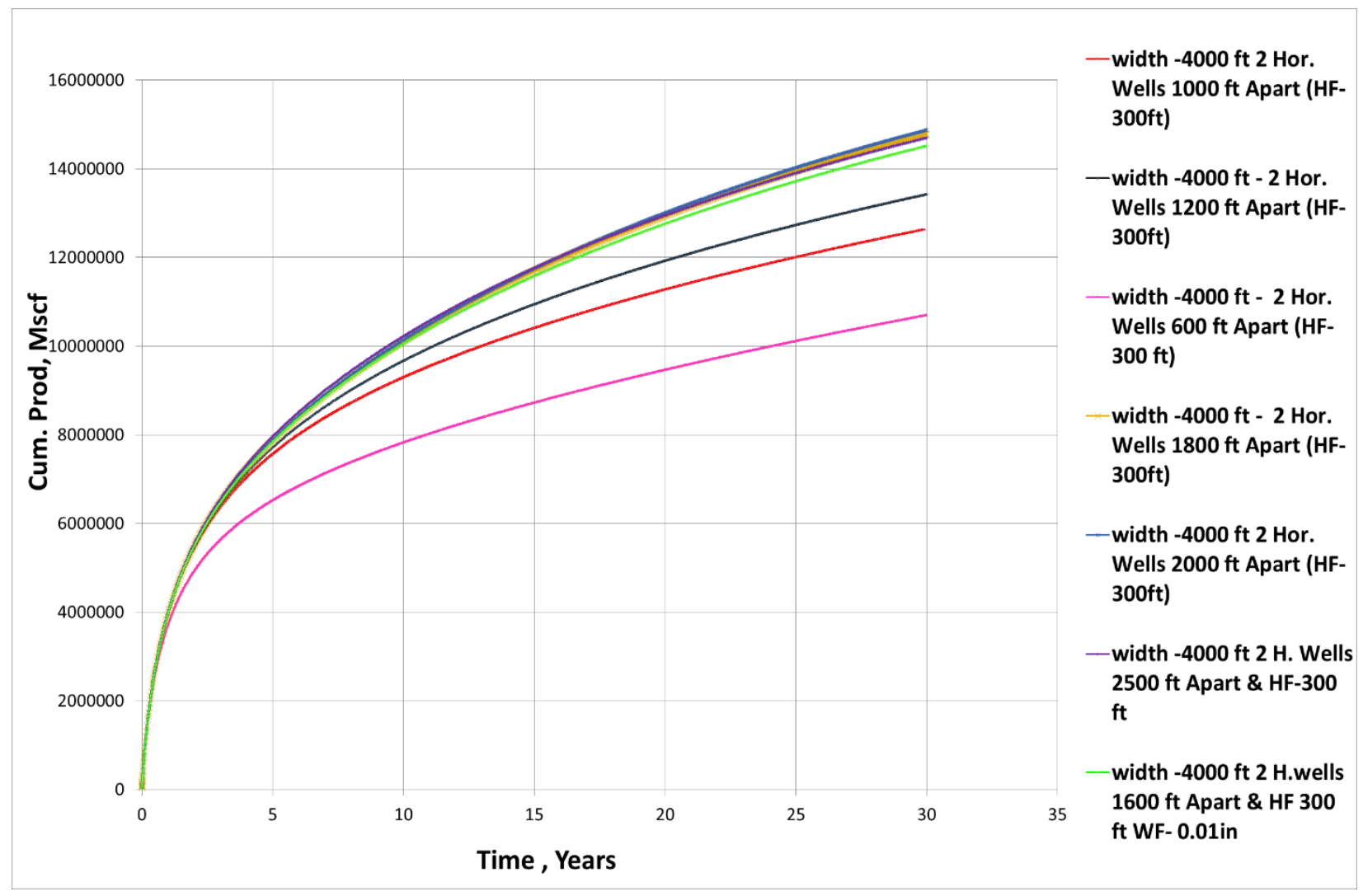

Figure B.2: Cumulative Production results vs. Time of hydraulically fractured horizontal lateral(s) - Results of Run 32, 33, 34, 35, 36, 37, and 38 in Table 4.

To further investigate our findings, the width of the hydraulic fractured horizontal wells, which is another property of hydraulic fracture, was doubled to 0.02 in. in Run 39, Run 40, and Run 41. As it can be seen in Figure B.3 below, doubling the width of hydraulic fractures does not impact our previous finding. 


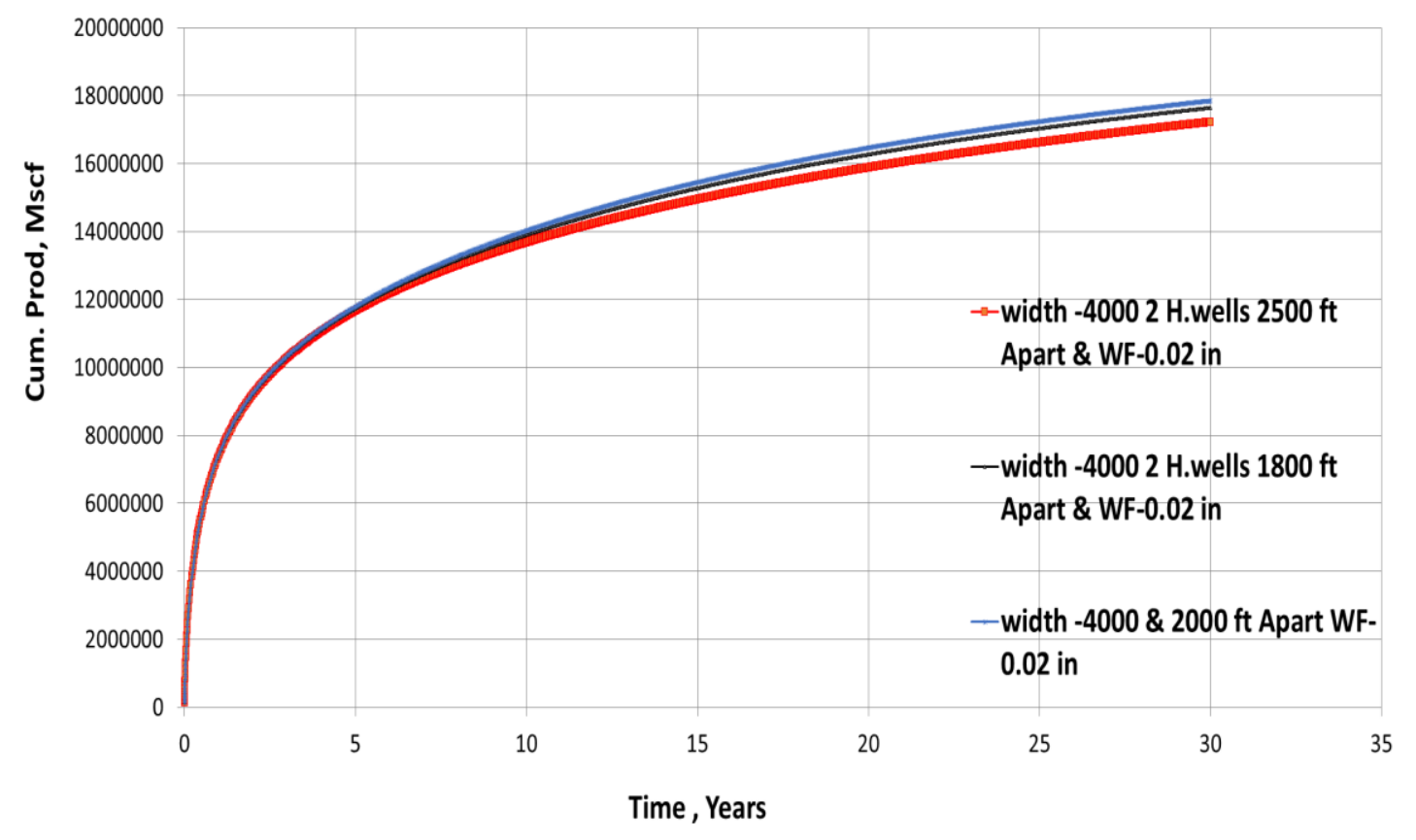

Figure B.3: Cumulative Production results vs. Time of hydraulically fractured horizontal lateral (s) - Results of Run 39, 40, and 41 in Table 4.

Furthermore, looking at the production profiles of two hydraulically fractured horizontal wells with half-length of $300 \mathrm{ft}$. where the width is doubled to 0.02 in. as in Run 42, Run 43, and Run 44 in Figure B.4; the production performance of these wells are all identical. This shows once more that in a drainage area where two horizontal wells are placed together, the further away they are from each other such that there is lesser and lesser interference between them, and given their proper and reasonable distance away from the boundaries, the better their recovery.

The same finding is valid for the case of two hydraulically fractured horizontal laterals with a halflength of $300 \mathrm{ft}$. and width of 0.005 in. in Run 45, Run 46, and Run 47 as illustrated in Figure B.5; though the production clearly decreases as expected (as the width of the hydraulic fracture decreases, the drainage area decreases as well). 
Figure B.6 shows the production profiles of two hydraulically fractured horizontal laterals, half-length and width respectively $500 \mathrm{ft}$. and 0.01 in., but this time the fissures permeability and the matrix permeability of the fractures of the formation are doubled as in Run 48, Run 49, Run 50, and Run 51. Their production profiles results support our finding that interference between wells and proximity to boundaries impact on production; in this instance, increasing the permeability of our formation most definitely will increase the drainage area of two horizontal wells taking into account the initial model parameters to develop the base model, therefore, creating more communication/interference as the wells get closer to each other or as they get closer to the boundaries.

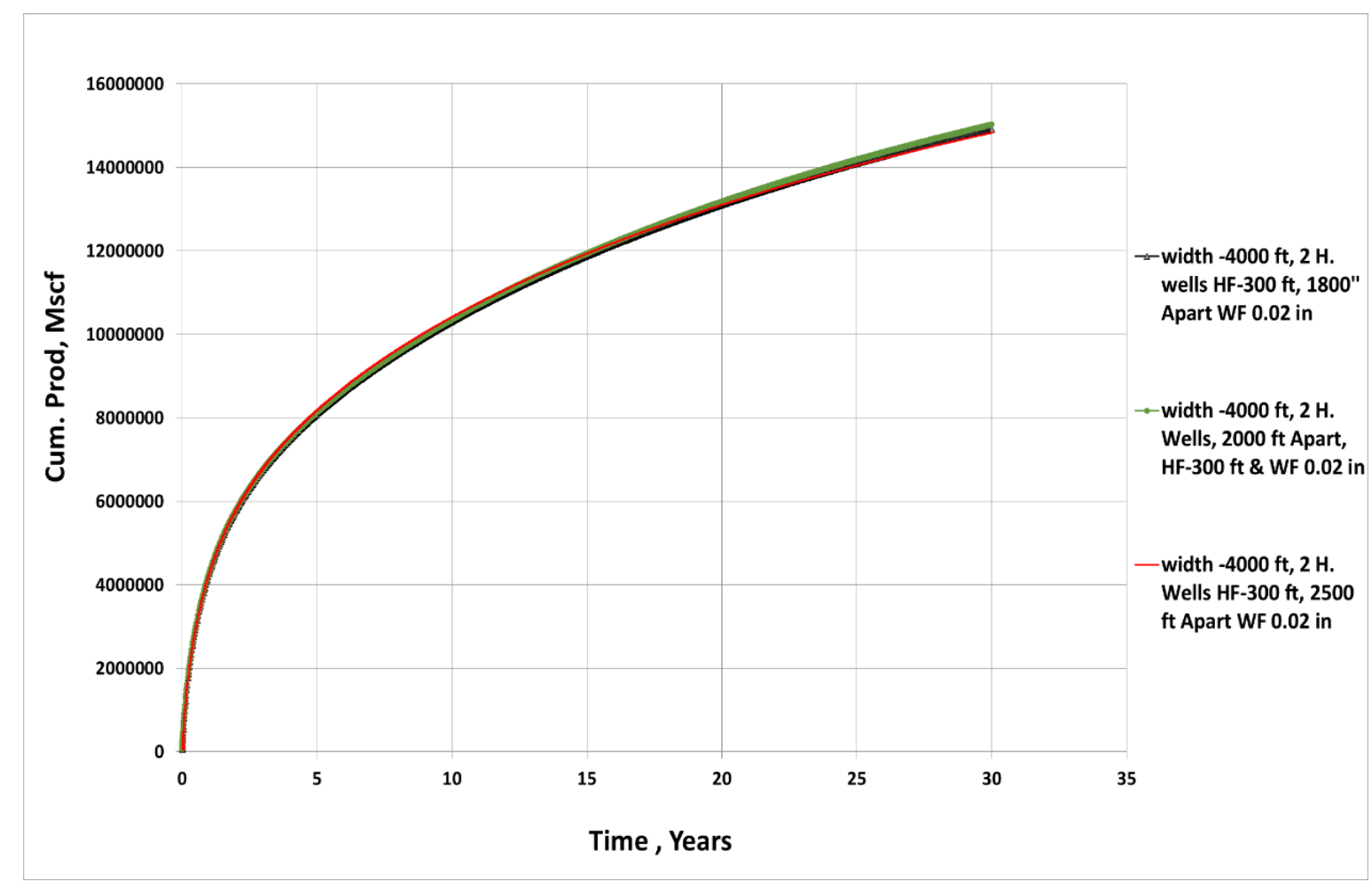

Figure B.4: Cumulative Production results vs. Time of hydraulically fractured horizontal lateral(s) - Results of Run 42, 43, and 44 in Table 4.

The production profiles of two hydraulically fractured horizontal laterals, with half-length and width respectively $300 \mathrm{ft}$. and 0.01 in. as in Run 52, Run 53, and Run 54 also support our finding as illustrated in Figure B.7. 
Appendix $\mathbf{C}$ is provides the preliminary analysis to determine the practical dimensions for the drainage area in this study.

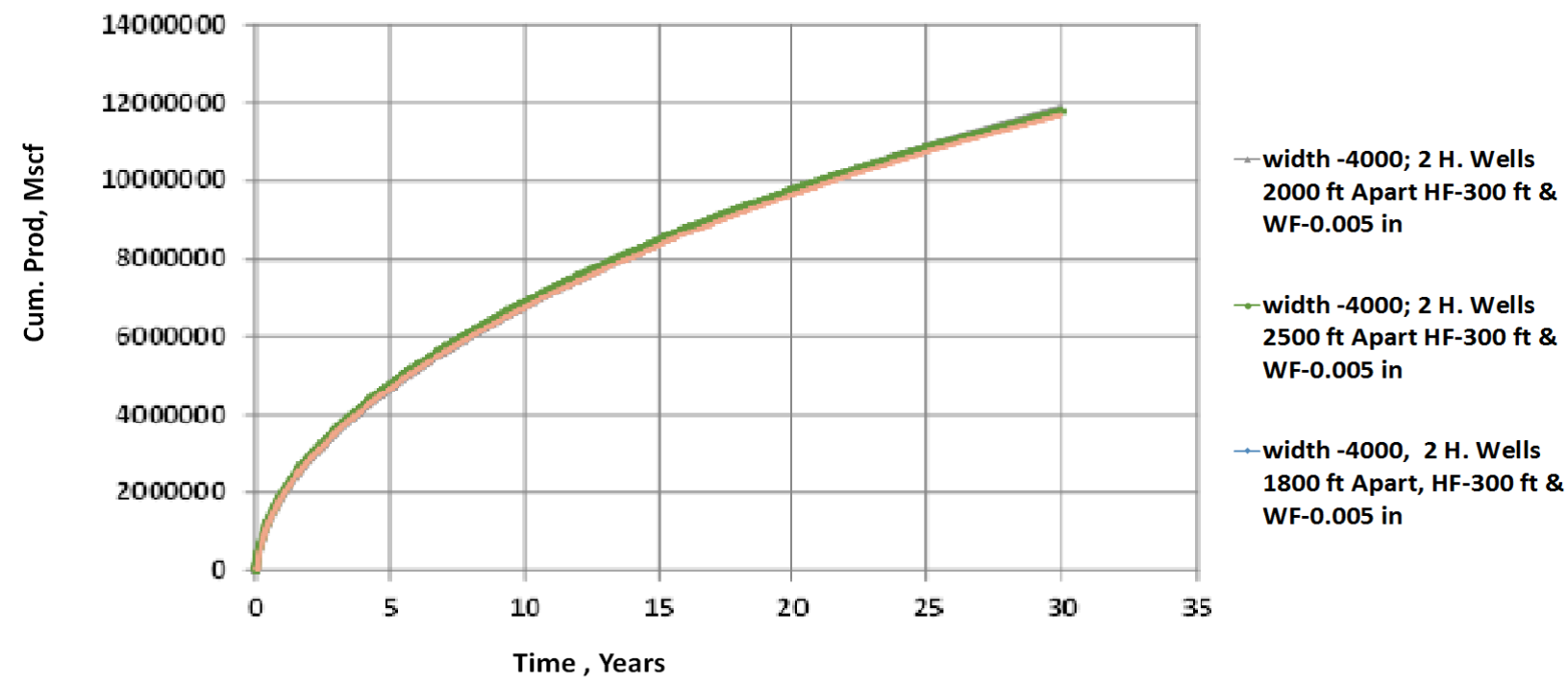

Figure B.5: Cumulative Production results vs. Time of hydraulically fractured horizontal lateral(s) - Results of Run 45, 46, and 47 in Table 4.

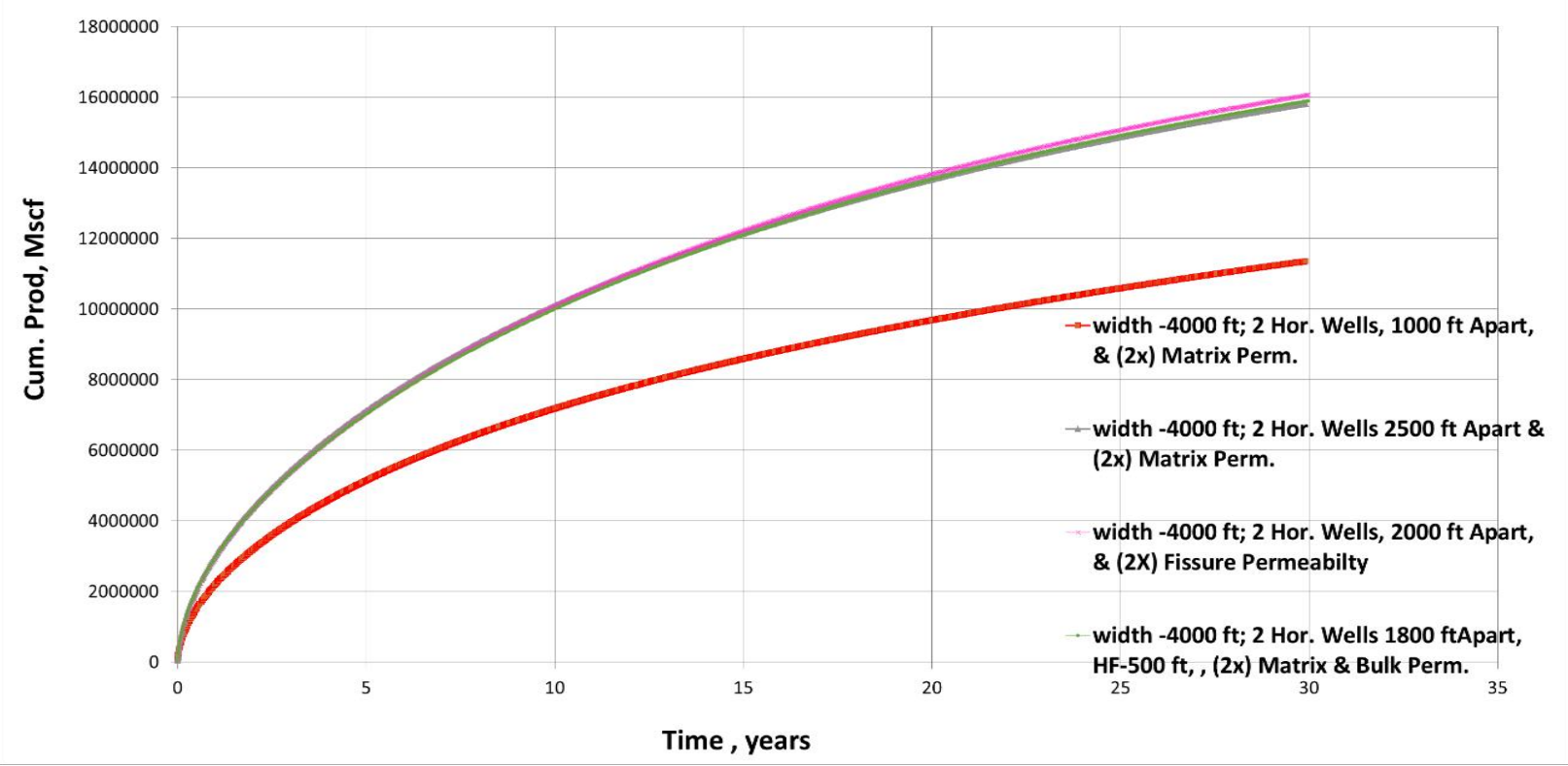

Figure B.6: Cumulative Production results vs. Time of hydraulically fractured horizontal lateral(s) - Results of Run 48, 49, 50, and 51 in Table 4. 


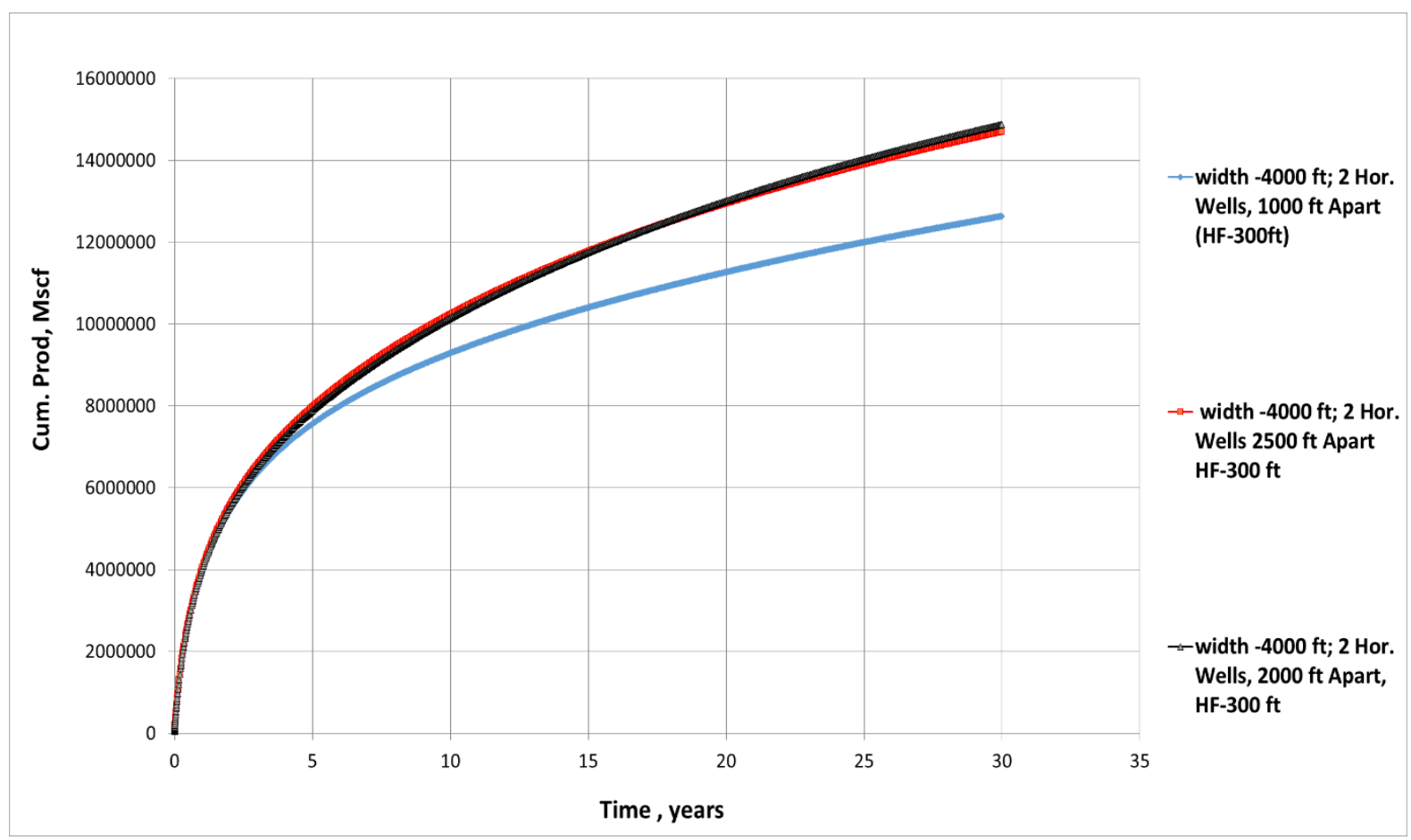

Figure B.7: Cumulative Production results vs. Time of hydraulically fractured horizontal lateral(s) - Results of Run 52, 53, and 54 in Table 4. 


\section{CONCLUSION}

The main goal for this study was to investigate the impact of well spacing on the production performance of hydraulically fractured horizontal laterals in low permeability formations such as Marcellus shale.

For this particular research project, and for economic purpose, it was determined that:

- $\quad$ One well was not enough to drain and economically maximize the recovery of an area of $8000 \mathrm{ft}$. $\times 4000 \mathrm{ft}$.

- For drainage area of $8000 \mathrm{ft} . \times 4000 \mathrm{ft}$., two horizontal laterals with 25 hydraulically fractured stages and spaced $2000 \mathrm{ft}$. apart, were the most adequate case to efficiently drain the area.

- The half-length of the fracture plays a significant role in increasing the drainage area and consequently the production.

- The width of the fracture has no significant effect on the well spacing.

The following conclusions were then attained:

- Geometry, symmetry, and distance of the wells have a significant impact on the recovery from the reservoir.

- Hydraulic fractures help increase the drainage area of horizontal wells; however, the lateral spacing chosen between wells must be carefully considered, as it is evident that interference or communication between the hydraulic fractures in their respective drainage area may take place during production 


\section{REFERENCES}

Aminian, Kashy. "Lecture 9: Horizontal Wells." PowerPoint presentation. West Virginia University, Morgantown, WV. 18 April 2013.

“AEO 2014 Early Release Overview: Energy Productions and Imports.” eia.gov. U.S. Energy Information Administration, December 16, 2013. Web. 5 May, 2014.

Aminian, K., Ameri, S., Saradji, M.S., Locke, C.D. (1985) A Study of Reservoir Parameters Affecting Gas Spacing in West Virginia. SPE 14517.

Belvalkar, R. A., \& Oyewole, S. (2010) Development of Marcellus Shale in Pennsylvania. SPE 134852.

Carpenter, Chris. "Optimized Shale-Resource Development: Well Placement and Hydraulic-Fracture Stages”. Journal of Petroleum Technology (JPT) Oct. 2013: 116-119. Print.

Crouse, C. Phillip. Application and Needs for Advanced Multilateral Technologies and Strategies. n.d. Web. 6 June 2014. doe.gov. 〈http://www.netl.doe.gov/KMD/Cds/disk28/NG2-5.PDF>.

Economides, J. Michael, \& Martin, Tony. Modern Fracturing: Enhancing Natural Gas Production. Houston: Energy Tribune Publishing Inc., 2007. Print.

Fanchi, R. John. Principles of Applied Reservoir Simulation. Burlington, MA: Elsevier, 2006. Google books. Web. 21 May. 2014. <http://books.google.com>

Joshi, S.D. Horizontal Well Technology. Tulsa: Penn Well Publishing Company, 1991. Print.

Nelson, Belyadi, Mashayekhi, Aminian, Ameri. (2014) Predicting Long-Term Production Behavior of the Marcellus Shale. SPE 169489.

"Pad drilling and rig mobility lead to more efficient drilling." Eia.gov. U.S. Energy Information Admistration, September 11, 2012. Web. 15 April, 2014

Pearson, C. Mark. (2001) Dimensionless Fracture Conductivity: Better Input Values Make Better Wells. SPE 60184.

"Review of Emerging Resources: U.S. Shale Gas and Shale Oil Plays" eia.gov. U.S. Information Administration, July, 2011. Web. 30 April, 2014.

Wang, Cong., \& Wu, Yu-Shu. (2014) Modeling Analysis of Transient Pressure and Flow Behavior at Horizontal Well with Multi-Stage Hydraulic Fractures in Shale Gas Reservoirs. SPE 168966. 


\section{APPENDIX \\ Appendix A (Objective 1 - Figures of production results)}

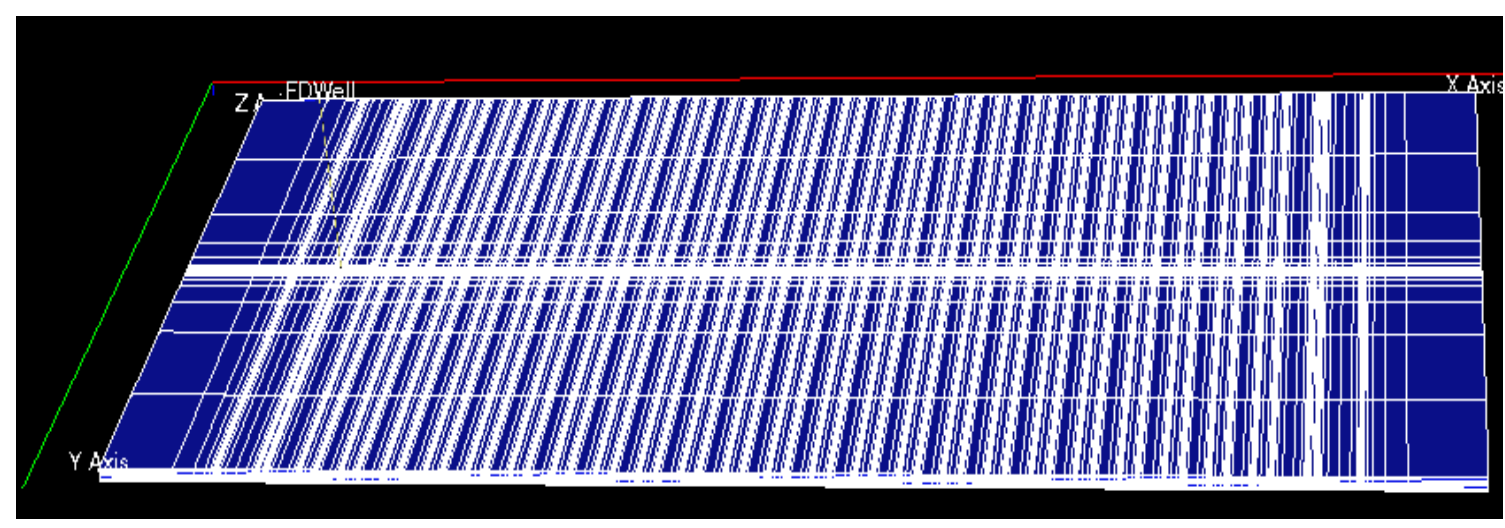

Figure 13: Generated chosen-model $4000 \mathrm{ft} . \times 2000 \mathrm{ft}$. containing one horizontal well with 13 hydraulic fractures to be doubled to then obtain our base model

From the analysis of the production performance of the models in figures $14,15,16,17,18,19,20$, and

21 , it can be summed up that:

- There is a better recovery from a 13 hydraulic fractured lateral horizontal well than there is with a

7 hydraulic fractured lateral horizontal well considering all the drainage areas.

- After careful analysis, it can be noticed that the models with a single lateral horizontal well and 13 hydraulic fractures (250 feet hydraulic fractures spacing), confined in drainage areas with a width of $4000 \mathrm{ft}$. and $2000 \mathrm{ft}$, have a close (almost the same cumulative production results) recovery during 30 years of production; or in some cases, the production starts to deviate or separate between 15 and 20 years of production. In petroleum economics, especially in the Marcellus development, the first 5 to 10 years of production are the most profitable; the remnant years of production beyond the first 10 years are not quite seriously considered during early development of a reservoir in the Marcellus. (Belvalkar, R. \& Oyewole, S., 2010).

- Also, a hydraulic fractured horizontal well with half-length of $500 \mathrm{ft}$. has a better recovery than one with a half-length of $300 \mathrm{ft}$. for all the models. That said, the half-length of a hydraulic fracture has a great impact on production. 


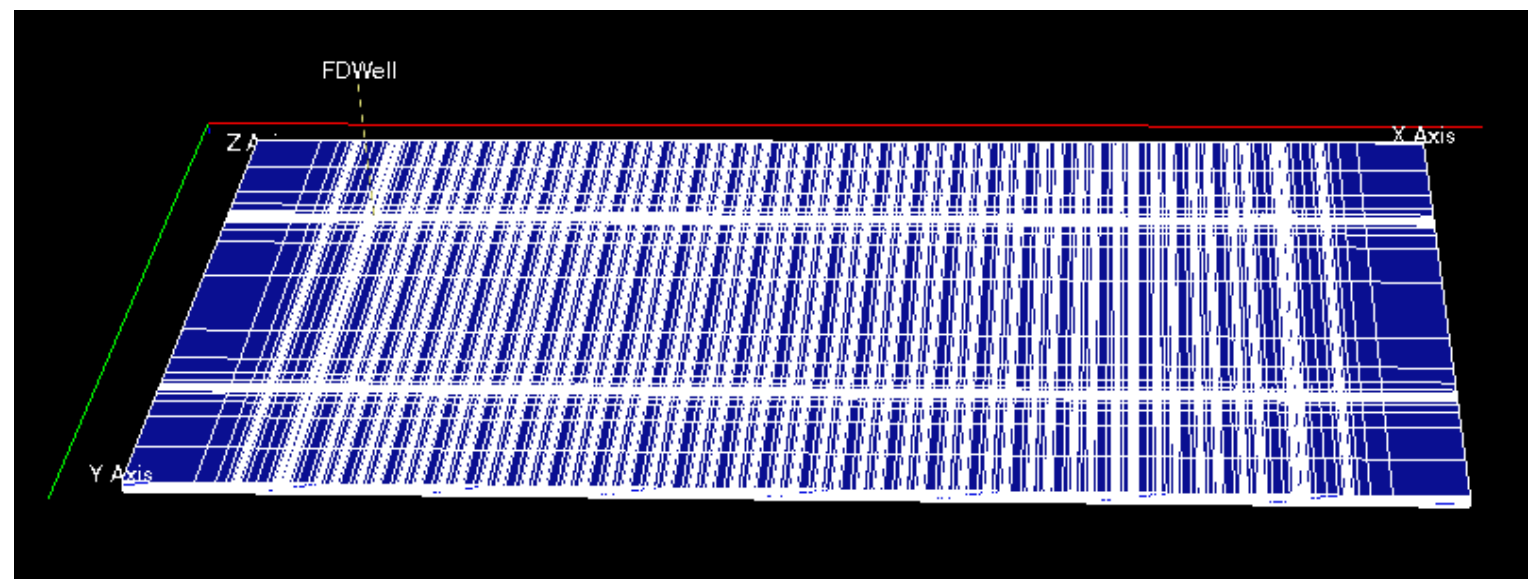

Figure 12: Generated base model $8000 \times 4000 \mathrm{ft}^{2}$ containing two horizontal wells with 25 hydraulic fractures each.

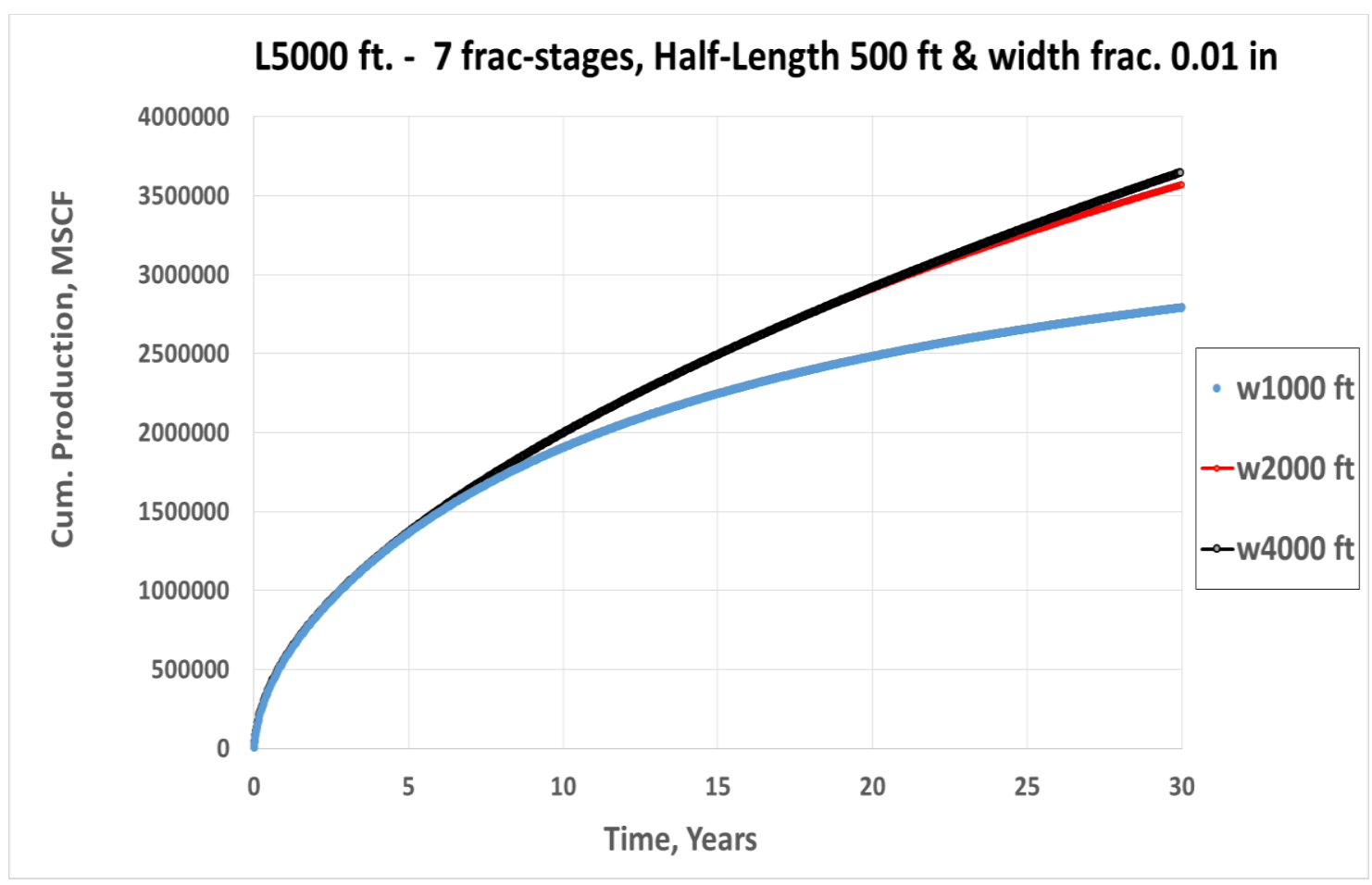

Figure A.1: Cumulative Production results vs. Time of 1 hydraulically fractured horizontal lateral(s) - Results of Runs 1, 2, and 3 in Table 3 


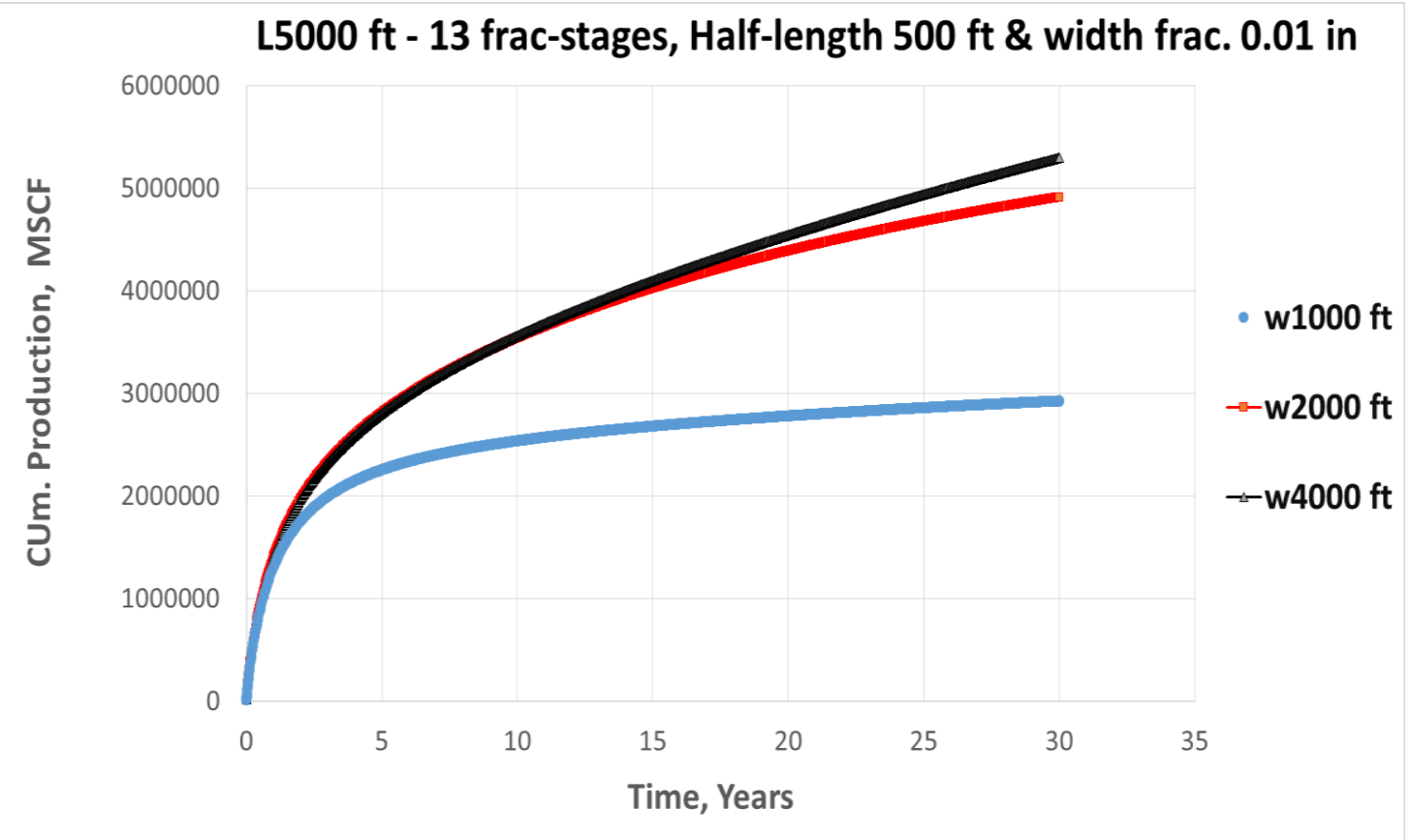

Figure A.2: Cumulative Production results vs. Time of hydraulically fractured horizontal Lateral(s) - Results of Run4, 5, and 6 in Table 3

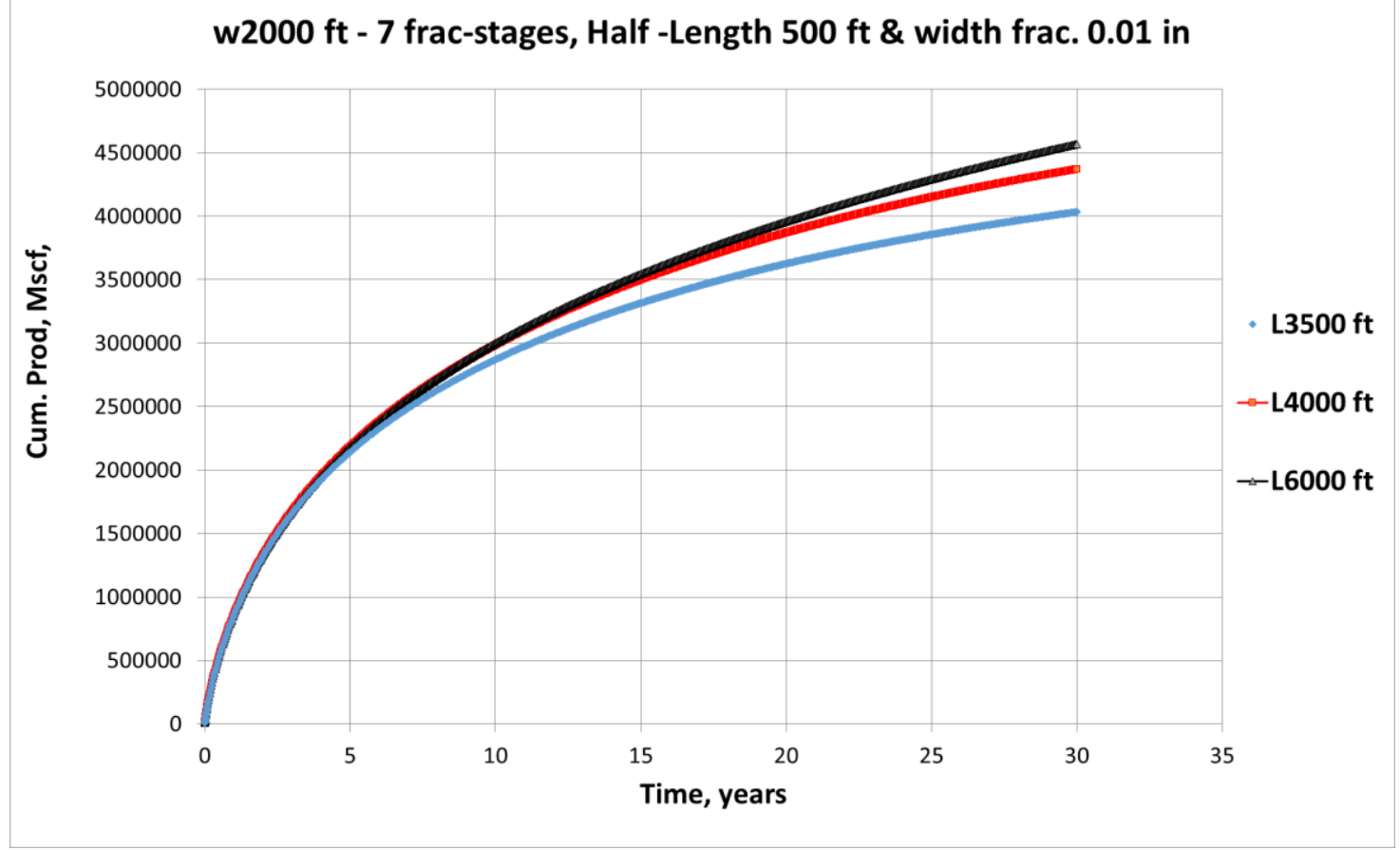

Figure A.3: Cumulative Production results vs. Time of hydraulically fractured horizontal lateral(s) - Results of Run 7, 8, and 9 in Table 3 


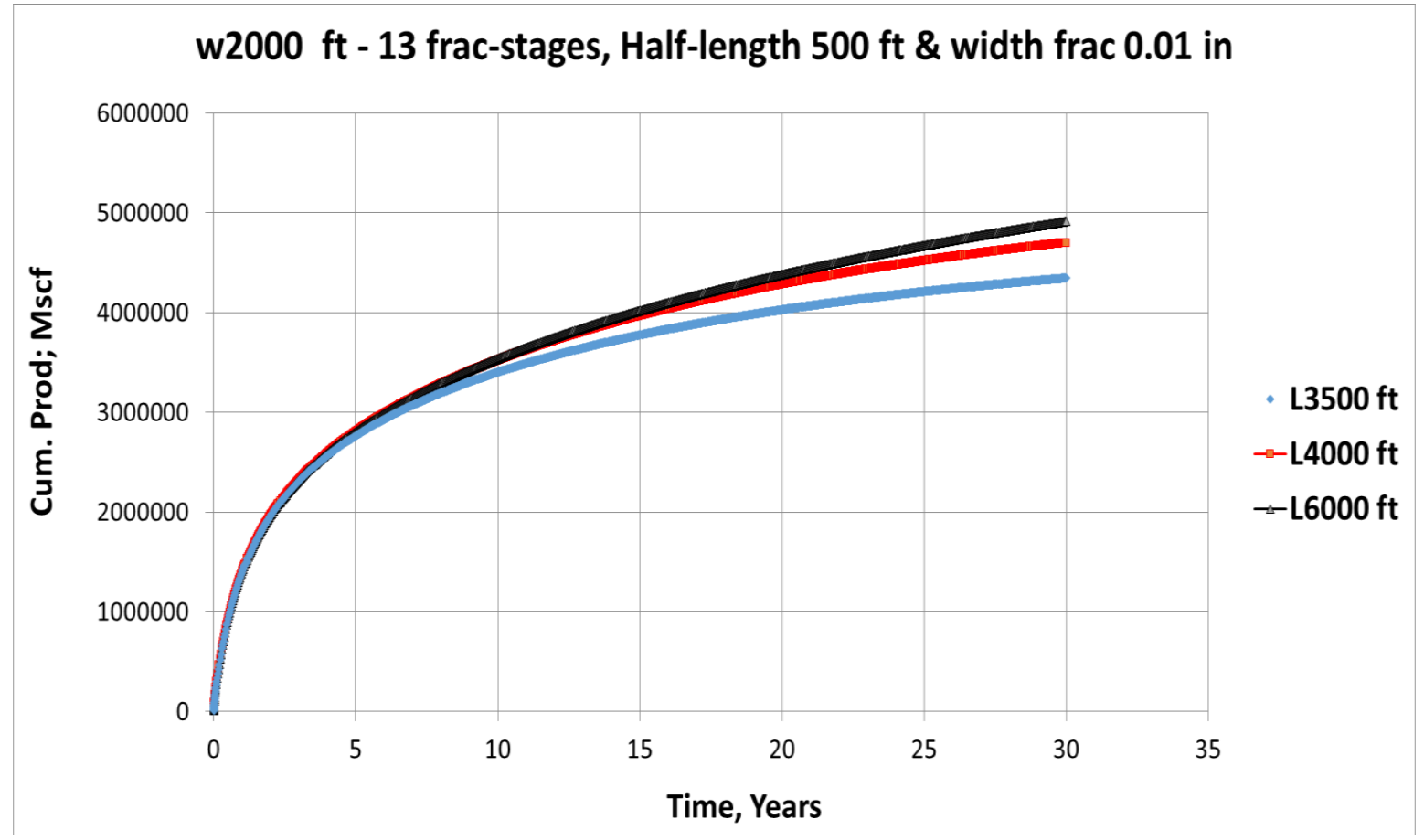

Figure A.4: Cumulative Production results vs. Time of hydraulically fractured horizontal lateral(s) - Results of Run 10, 11, and 12 in Table 3

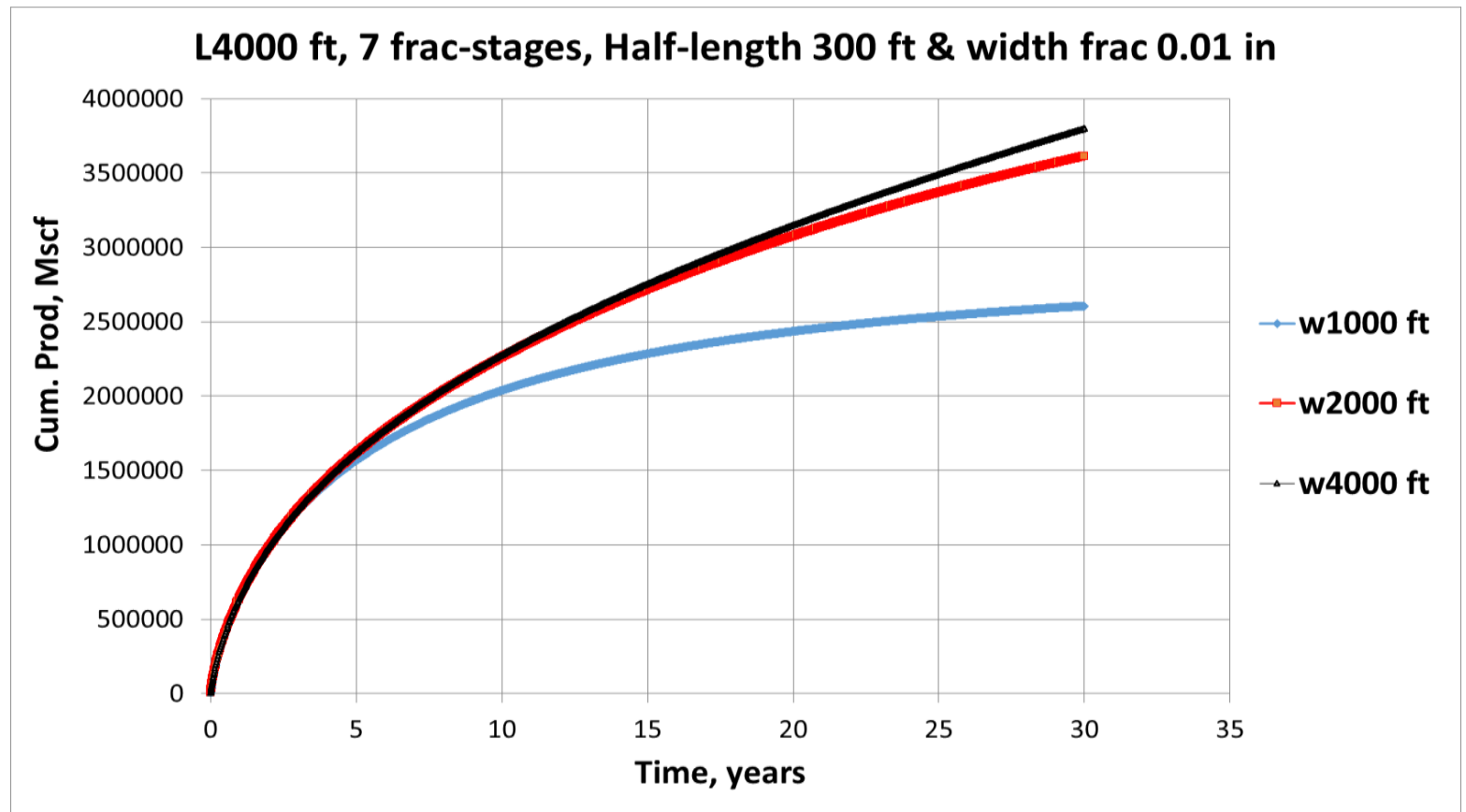

Figure A.5: Cumulative Production results vs. Time of hydraulically fractured horizontal lateral(s) - Results of Run 13, 14, and 15 in Table 3 


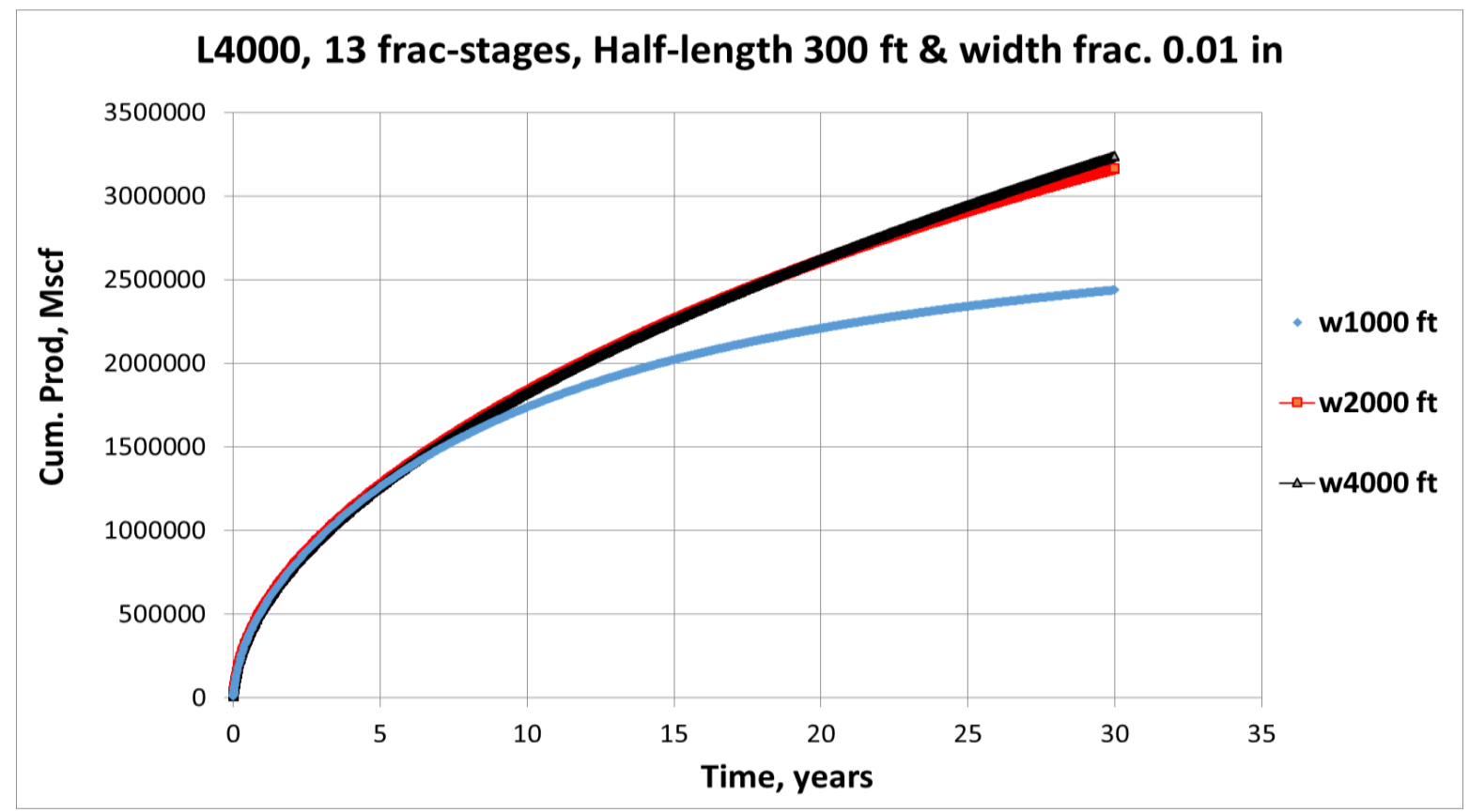

Figure A.6: Cumulative Production results vs. Time of hydraulically fractured horizontal lateral(s) - Results of Run 16, 17, and 18 in Table 3

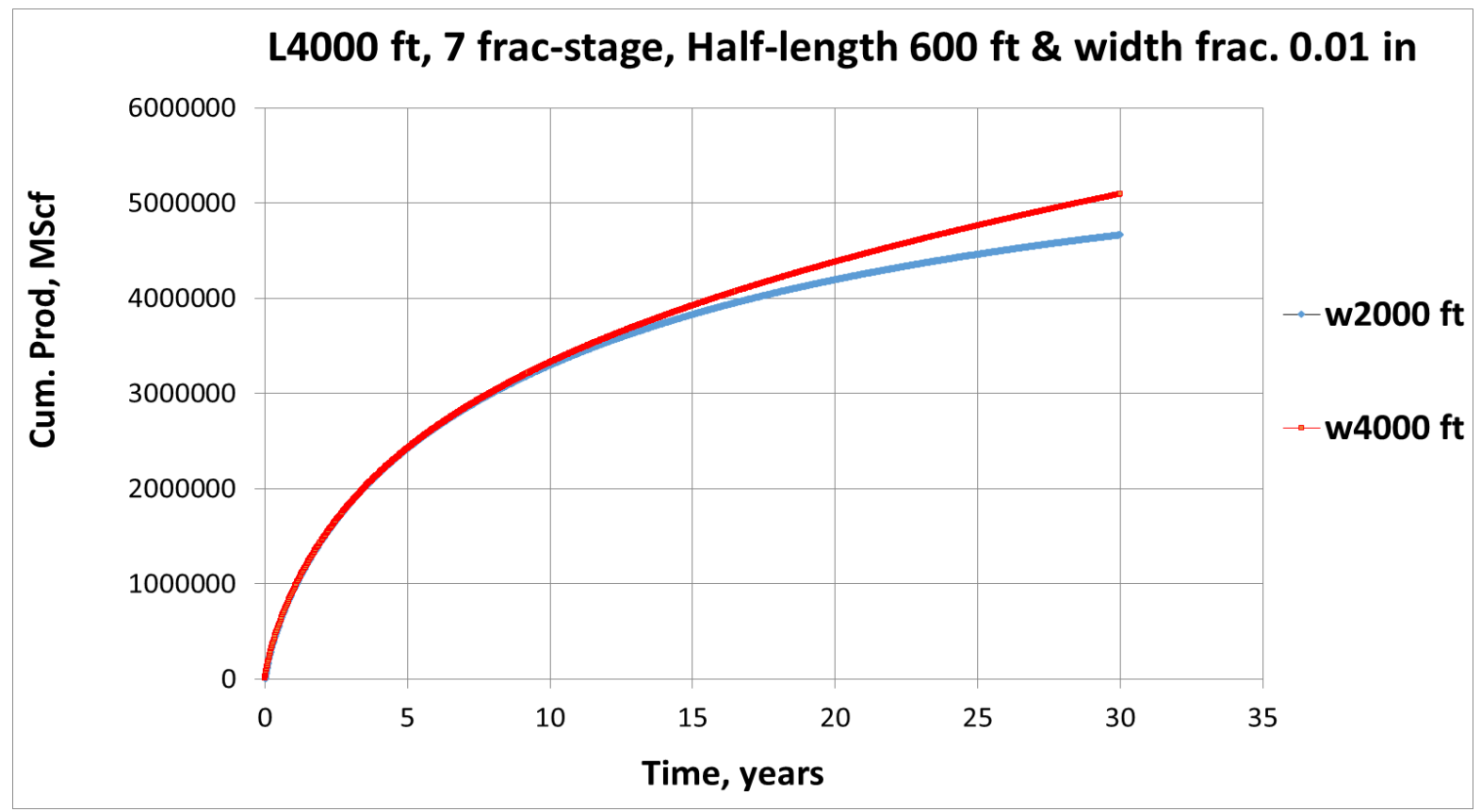

Figure A.7: Cumulative Production results vs. Time of hydraulically fractured horizontal lateral(s) - Results of Run 19, 20, and 21 in Table 3 


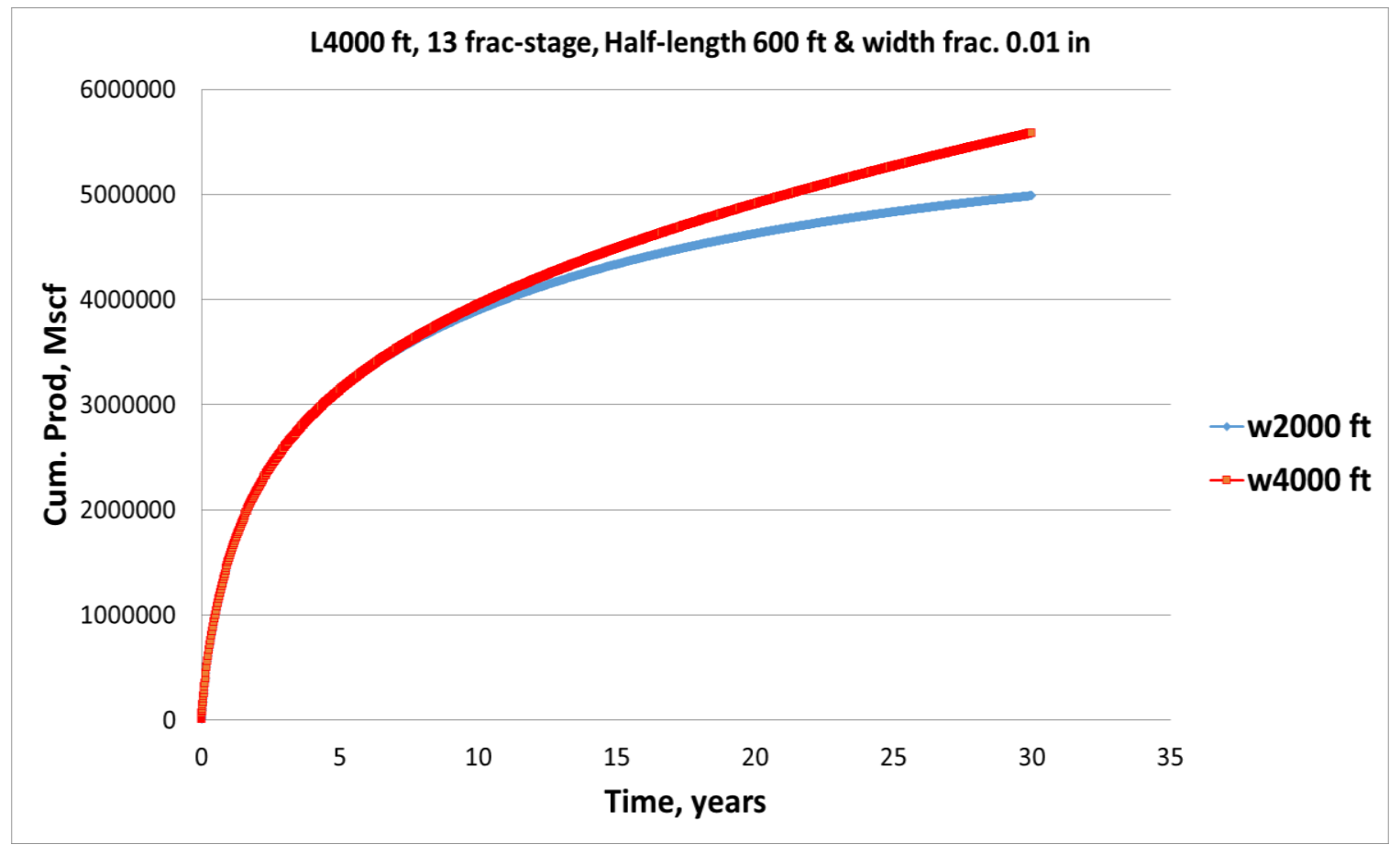

Figure A.8: Cumulative Production results vs. Time of hydraulically fractured horizontal lateral(s) - Results of Run 22, 23, and 24 in Table 3

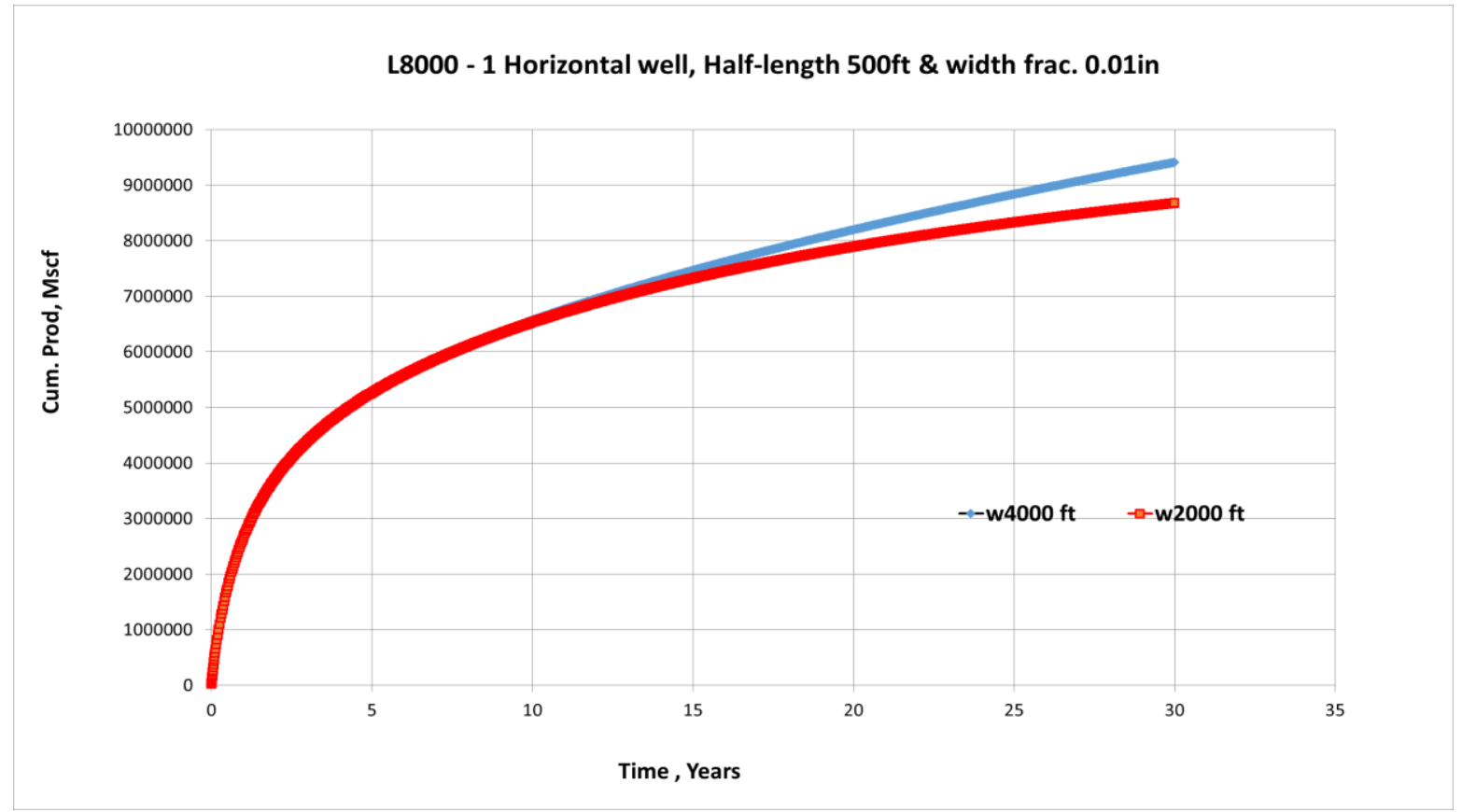

Figure A.9: Cumulative Production results vs. Time of hydraulically fractured horizontal lateral(s) - Results of Run 25 and 26 in Table 3 


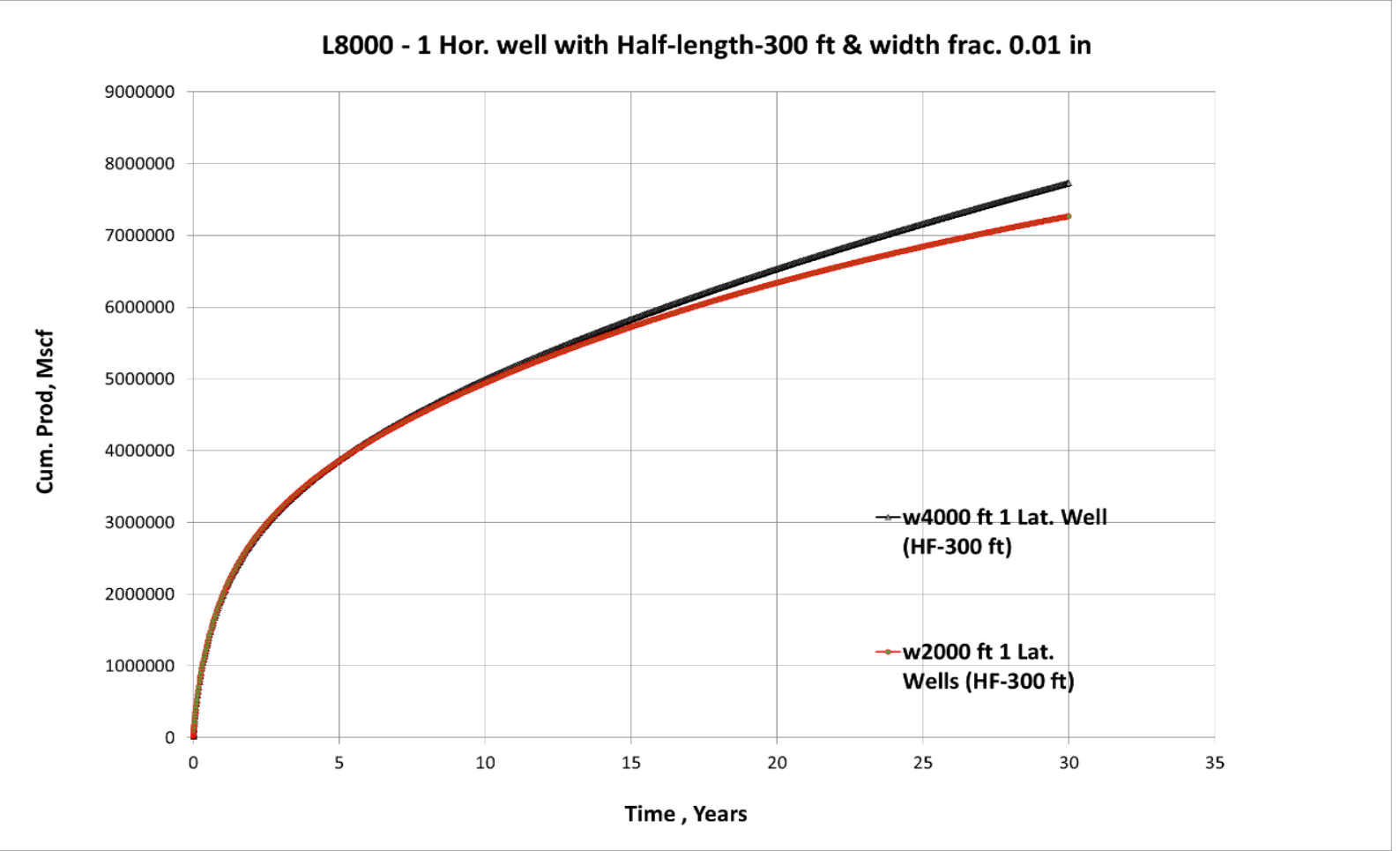

Figure A.10: Cumulative Production results vs. Time of hydraulically fractured horizontal lateral(s) - Results of Run 27 and 28 in Table 3 


\section{Appendix B (Objective 2 - Figures of production results)}

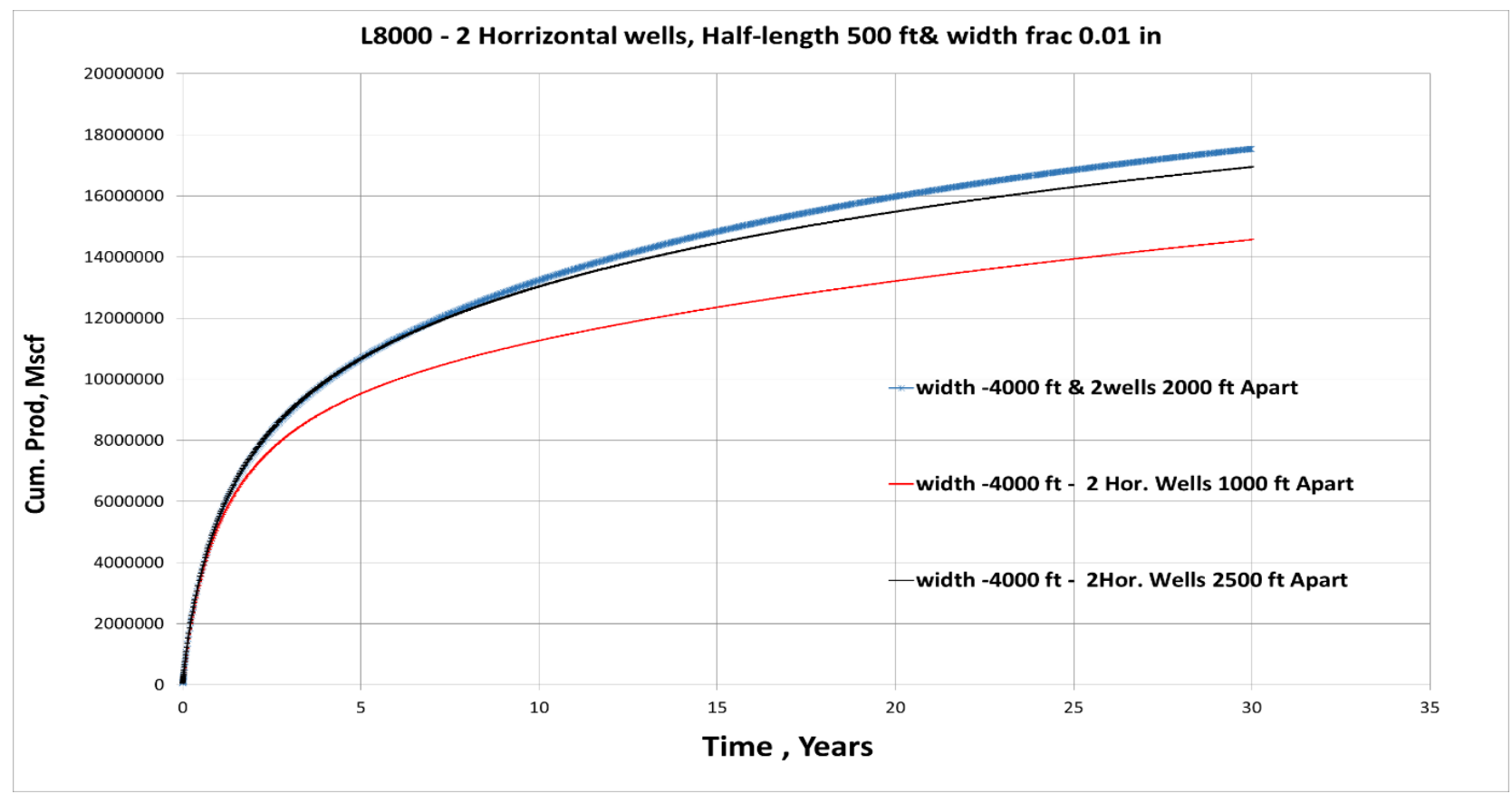

Figure B.1: Cumulative Production results vs. Time of hydraulically fractured horizontal lateral(s) - Results of Run 29, 30, and 31 in Table 4.

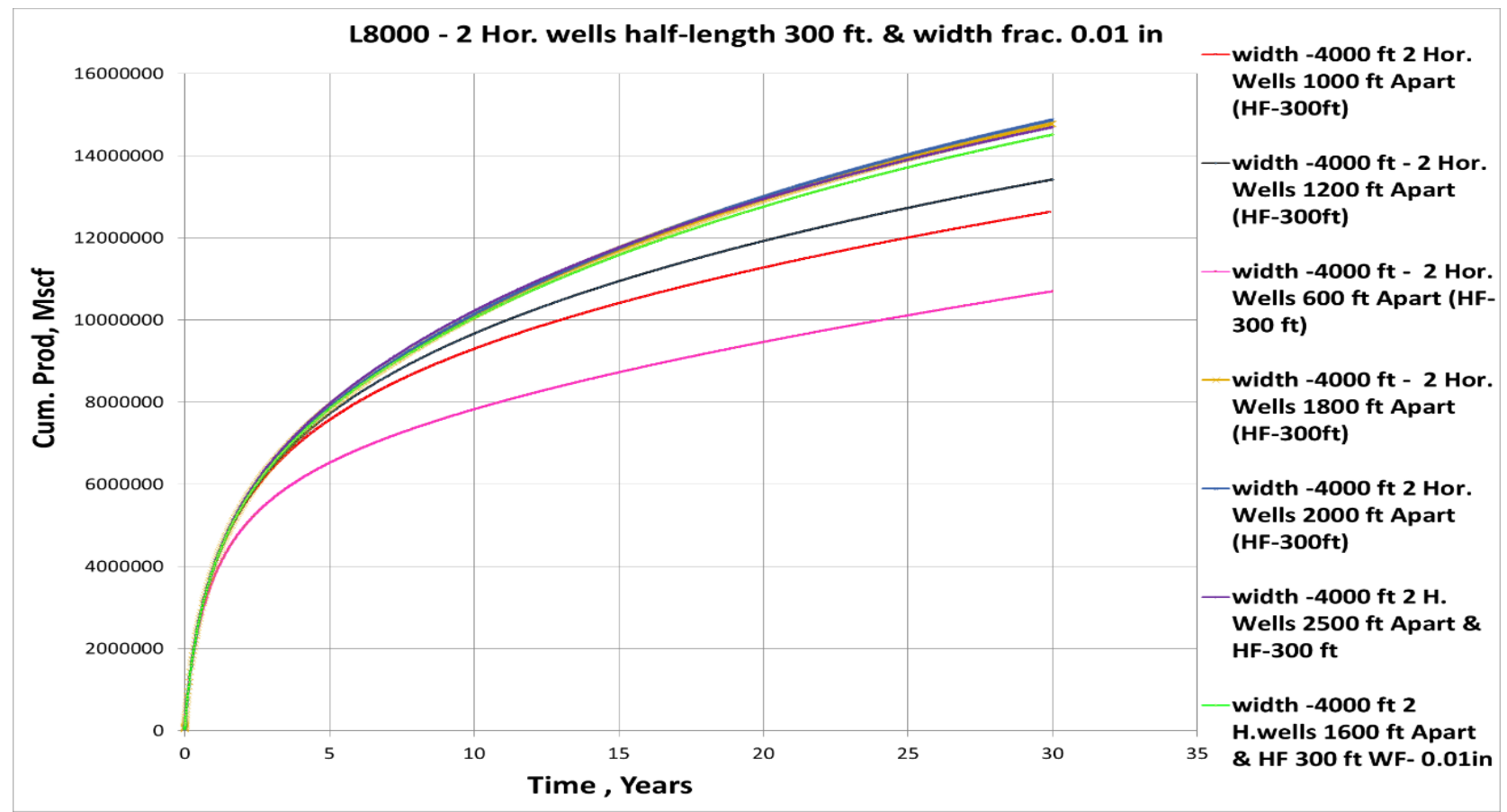

Figure B.2: Cumulative Production results vs. Time of hydraulically fractured horizontal lateral(s) - Results of Run 32, 33, 34, 35, 36, 37, and 38 in Table 4. 


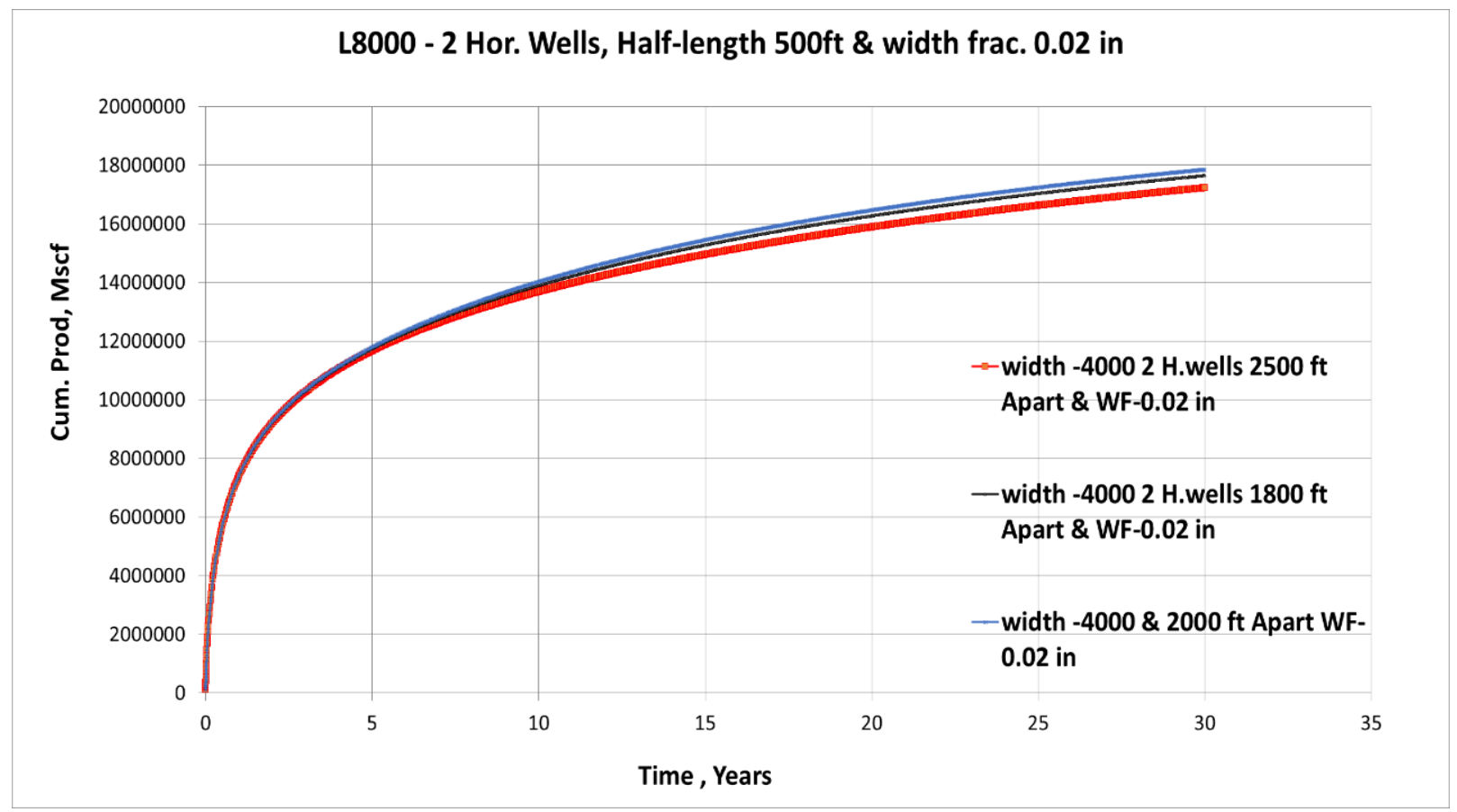

Figure B.3: Cumulative Production results vs. Time of hydraulically fractured horizontal lateral(s) - Results of Run 39, 40, and 41 in Table 4.

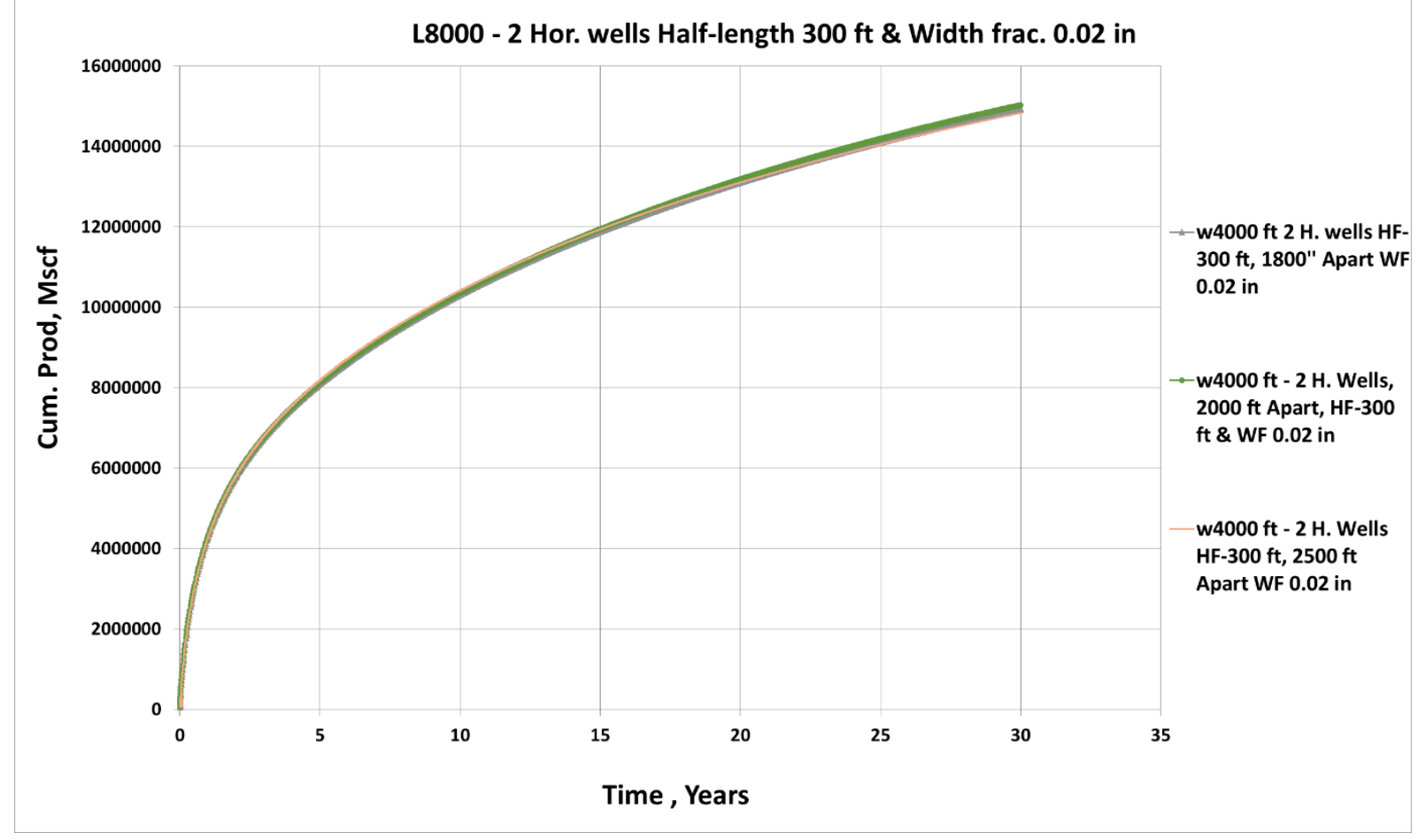

Figure B.4: Cumulative Production results vs. Time of hydraulically fractured horizontal lateral(s) - Results of Run 42, 43, and 44 in Table 4. 


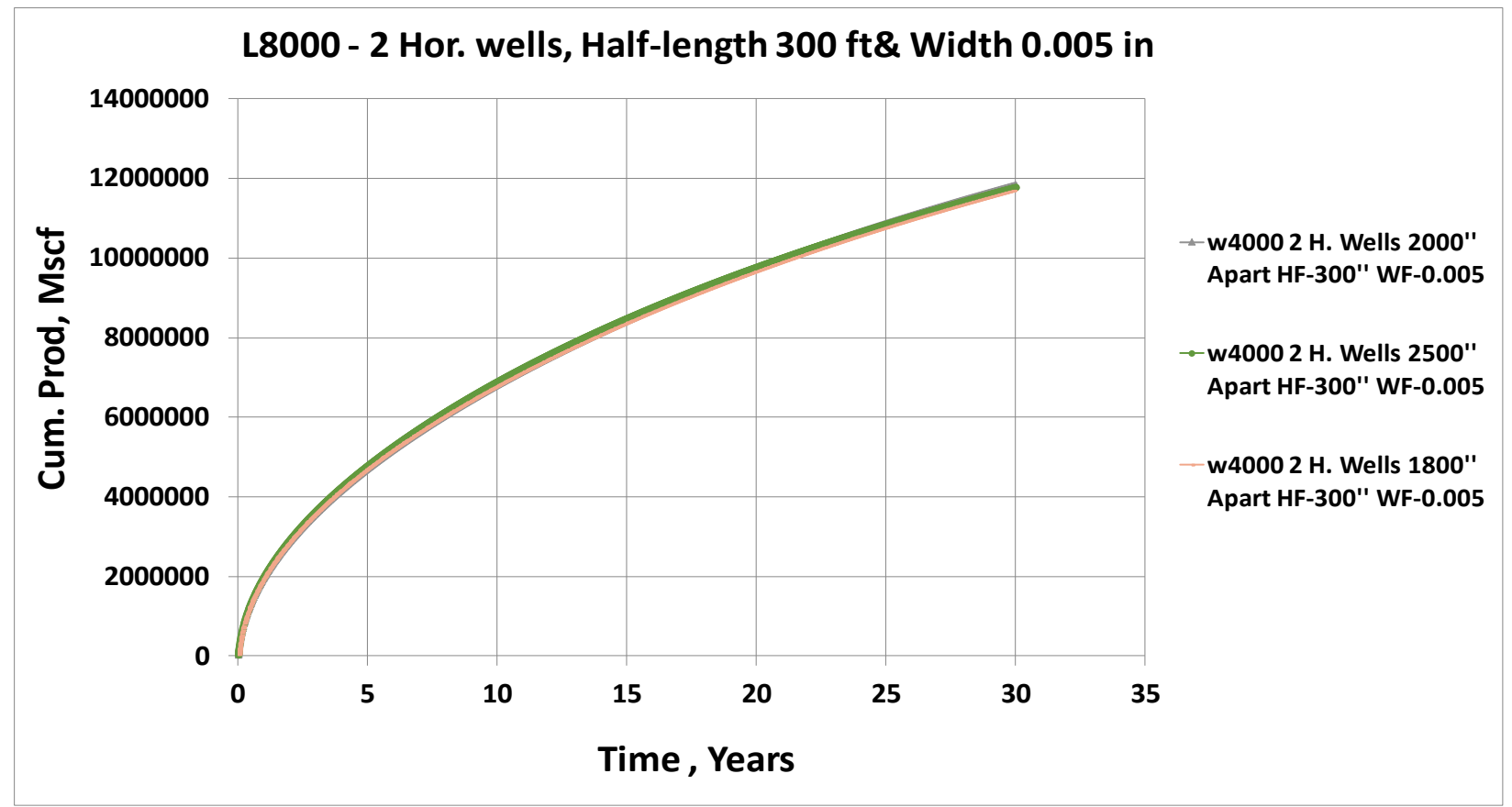

Figure B.5: Cumulative Production results vs. Time of hydraulically fractured horizontal lateral(s) - Results of Run 45, 46, and 47 in Table 4.

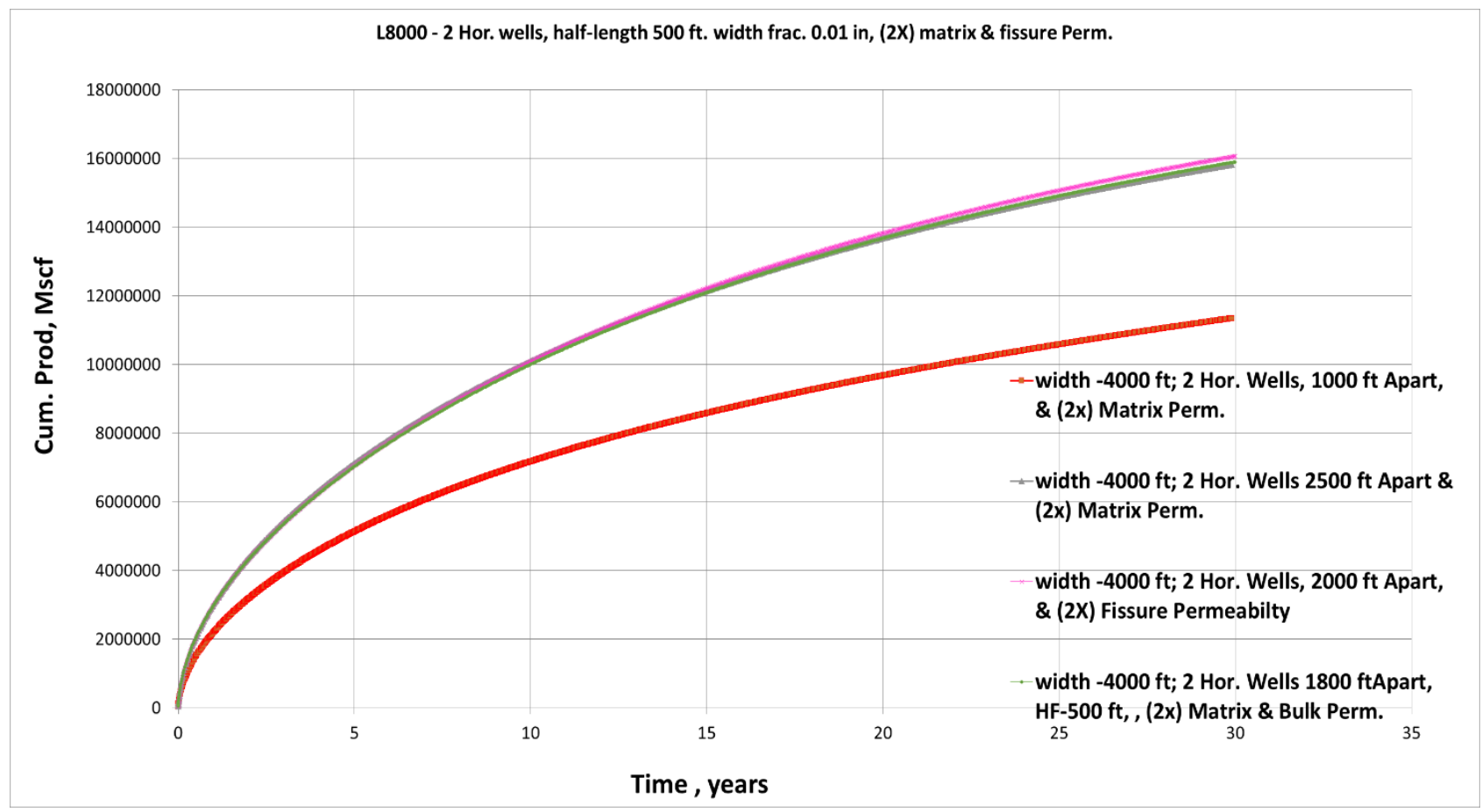

Figure B.6: Cumulative Production results vs. Time of hydraulically fractured horizontal lateral(s) - Results of Run 48, 49, 50, and 51 in Table 4. 


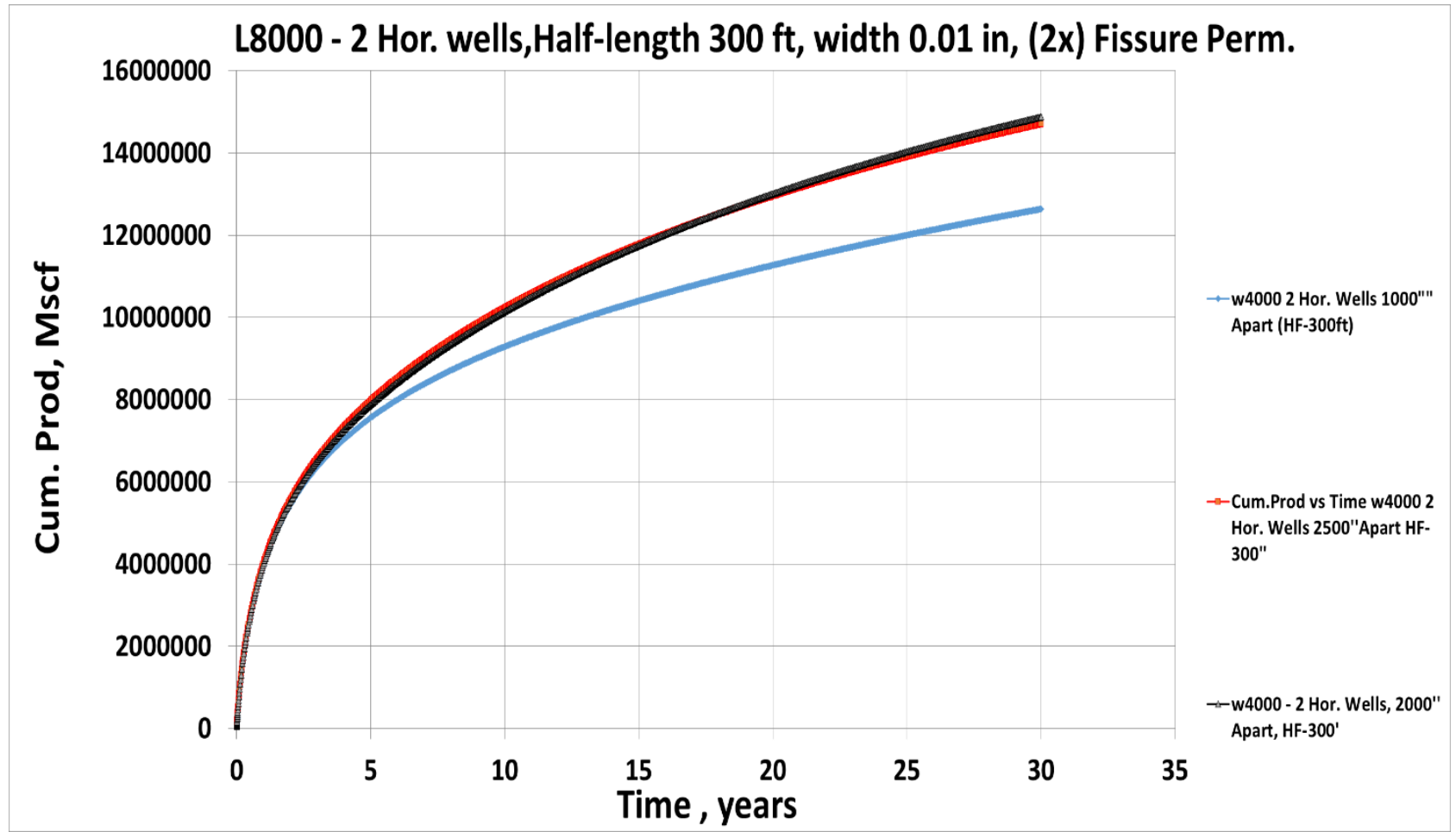

Figure B.7: Cumulative Production results vs. Time of hydraulically fractured horizontal lateral(s) - Results of Run 52, 53, and 54 in Table 4. 


\section{Appendix C (Discussions)}

After asserting our findings, many questions arise from our research. If a bigger or smaller reservoir was to be developed, how would the distance to place our wells between each other be picked? Or should a well be drilled or plugged instead? Should the half-length of the hydraulic fractures be increased? All these new valid suggestions would impact on the well spacing chosen for hydraulic fractured horizontal laterals, and consequently their production performance.

Many other scenarios could be added and considered to make this research study even more aspiring. Nevertheless, as to comment on a few of those suggestions, there is no proof till this day as the correct half-length or width of a fracture. Generally, it is more than the indicated or predicted one. Therefore, the chance of a fracture being in contact or close to boundaries is a possibility that can be encountered during development; and as depicted with production profiles simulated, interference between wells and the closer the drainage area is to the boundaries, the production starts declining. That is the reason of importance of evaluating all parameters to have a better analogy of all considered simulations, and even field operations. 